\title{
The long way down-are carbon and oxygen isotope signals in the tree ring uncoupled from canopy physiological processes?
}

\author{
Christine Offermann ${ }^{1,8}$, Juan Pedro Ferrio², Jutta Holst ${ }^{3}$, Rüdiger Grote ${ }^{4}$, Rolf Siegwolf ${ }^{5}$, \\ Zachary Kayler ${ }^{6}$ and Arthur Gessler 6,7
}

\begin{abstract}
${ }^{1}$ Centre for Systems Biology (ZBSA), University of Freiburg, Habsburgerstr. 49, D-79104 Freiburg, Germany; ${ }^{2}$ Department of Crop and Forest Sciences, ETSEA-University of Lleida, Avda. Rovira Roure 191, ES-25198 Lleida, Spain; ${ }^{3}$ Meteorological Institute, University of Freiburg, Werderring 10, 79085 Freiburg, Germany; ${ }^{4}$ Karlsruhe Institute of Technology (KIT), Institute for Meteorology and Climate Research, Kreuzeckbahnstr. 19, D-82467 Garmisch-Partenkirchen, Germany; ${ }^{5}$ Laboratory of Atmospheric Chemistry, Stable Isotopes and Ecosystem Fluxes, Paul Scherrer Institut, CH-5232 Villigen PSI, Switzerland; ${ }^{\prime}$ nstitute for Landscape Biogeochemistry, Leibniz-Centre for Agricultural Landscape Research (ZALF), Eberswalderstr. 84, 15374 Müncheberg, Germany; ${ }^{7}$ Corresponding author (gessler@zalf.de); ${ }^{8}$ Current address: Radiotherapy Clinic, University of Freiburg, Medical Physics, Robert-Koch-Strasse 3, 79106 Freiburg, Germany
\end{abstract}

Received June 8, 2011; accepted August 7, 2011; published online September 27, 2011; handling Editor James Ehleringer

The carbon $\left(\delta^{13} \mathrm{C}\right)$ and oxygen $\left(\delta^{18} \mathrm{O}\right)$ stable isotope composition is widely used to obtain information on the linkages between environmental drivers and tree physiology over various time scales. The tree-ring archive can especially be exploited to reconstruct inter- and intra-annual variation of both climate and physiology. There is, however, a lack of information on the processes potentially affecting $\delta^{13} \mathrm{C}$ and $\delta^{18} \mathrm{O}$ on their way from assimilation in the leaf to the tree ring. As a consequence, the aim of this study was to trace the isotope signals in European beech (Fagus sylvatica L.) from leaf water $\left(\delta^{18} \mathrm{O}\right)$ and leaf assimilates $\left(\delta^{13} \mathrm{C}\right.$ and $\left.\delta^{18} \mathrm{O}\right)$ to tree-ring wood via phloem-transported compounds over a whole growing season. Phloem and leaf samples for $\delta^{13} \mathrm{C}$ and $\delta^{18} \mathrm{O}$ analyses as well as soil water, xylem water, leaf water and atmospheric water vapour samples for $\delta^{18} \mathrm{O}$ analysis were taken approximately every 2 weeks during the growing season of 2007 . The $\delta^{13} \mathrm{C}$ and $\delta^{18} \mathrm{O}$ samples from the tree rings were dated intra-annually by monitoring the tree growth with dendrometers. $\delta^{18} \mathrm{O}$ in the phloem organic matter and tree-ring whole wood was not positively related to leaf water evaporative enrichment and $\delta^{18} \mathrm{O}$ of canopy organic matter pools. This finding implies a partial uncoupling of the tree-ring oxygen isotopic signal from canopy physiology. At the same time, internal carbon storage and remobilization physiology most likely prevented $\delta^{13} \mathrm{C}$ in tree-ring whole wood from being closely related to intra-annual variation in environmental drivers. Taking into account the post-photosynthetic isotope fractionation processes resulting in alterations of $\delta^{13} \mathrm{C}$ and $\delta^{18} \mathrm{O}$ not only in the tree ring but also in phloem carbohydrates, as well as the intra-annual timing of changes in the tree internal physiology, might help to better understand the meaning of the tree-ring isotope signal not only intra- but also inter-annually.

Keywords: evaporative enrichment, oxygen atom exchange, phloem transport, post-photosynthetic isotope fractionation.

\section{Introduction}

The stable isotope composition of carbon $\left(\delta^{13} \mathrm{C}\right)$ and oxygen $\left(\delta^{18} \mathrm{O}\right)$ in tree rings is widely used to reconstruct the climate of the past (McCarroll and Loader 2004) and/or to explore physiological reactions of trees to environmental conditions retrospectively. Both $\delta^{13} \mathrm{C}$ and $\delta^{18} \mathrm{O}$ were found to be strongly related to summer moisture conditions, especially in temperate regions (Treydte et al. 2007). Depending on species and sampling site, isotopic variations in the tree-ring archive were found to correlate with temperature $\left(\delta \mathrm{D}\right.$ and $\delta^{18} \mathrm{O}$ : Libby et al. $1976 ; \delta^{13} \mathrm{C}$ : Loader and Switsur 1996), humidity $\left(\delta^{18} \mathrm{O}\right.$ : Burk and Stuiver $1981 ; \delta^{13} \mathrm{C}$ : Ferrio and Voltas 2005), soil moisture and rainfall ( $\delta^{18} \mathrm{O}$ : Saurer et al. $1997 ; \delta^{13} \mathrm{C}$ : Leavitt 2007). The $\delta^{13} \mathrm{C}$ and $\delta^{18} \mathrm{O}$ of newly assimilated organic matter as well as of structural compounds in plant tissues mainly depend on two factors: (i) the isotopic composition of the inorganic 
source (i.e., atmospheric $\mathrm{CO}_{2}$ and soil water) and (ii) the isotope fractionation processes associated with transport, diffusion and phase transition as well as with enzyme reactions in the plant. Factor (ii) alters the original isotope signal of the source and imprints physiological information on the isotope composition of a given tissue (e.g., Farquhar et al. 1982, Farquhar and Cernusak 2005, Cernusak et al. 2009, Gessler et al. 2009b).

Primarily, the carbon and oxygen isotopic signal is imprinted on the newly assimilated sugars in the leaves during photosynthesis (Brugnoli et al. 1988). Together with the sugars, this signal is transported through the tree via the phloem before it is incorporated into the tree ring as structural organic matter after potential further fractionation steps. As a consequence of the photosynthetic carbon isotope fractionation, which is determined by the ratio $\left(c_{\mathrm{i}} / c_{\mathrm{a}}\right)$ of leaf intercellular $\left(c_{\mathrm{i}}\right)$ and ambient $\left(c_{a}\right) \mathrm{CO}_{2}$ concentration - or more precisely by $c_{\mathrm{c}} / c_{\mathrm{a}}\left(c_{\mathrm{c}}\right.$ : chloroplastic $\mathrm{CO}_{2}$ concentration; see Farquhar et al. 1982) - the $\delta^{13} \mathrm{C}$ of recent photosynthates and structural compounds derived from these assimilates has often been used to characterize environmental effects on the physiology of photosynthesis. Water limitation generally evokes reduced stomatal conductance and lower $c_{i}$ and thus leads to increased $\delta^{13} C$ in different plant tissues and chemical compounds (e.g., Farquhar et al. 1982, Korol et al. 1999, Keitel et al. 2003). Leaf internal $\mathrm{CO}_{2}$ concentration and $\delta^{13} \mathrm{C}$ are also influenced by photosynthetic capacity. As a consequence, light limitation of photosynthesis can lead to more negative $\delta^{13} \mathrm{C}$ values (Leavitt and Long 1986, McCarroll and Pawellek 2001), and combined influences of water and light availability have also been observed (Gessler et al. 2001).

The oxygen stable isotope composition $\left(\delta^{18} \mathrm{O}\right)$ or the oxygen isotopic enrichment above source water $\left(\Delta^{18} \mathrm{O}\right)$ of plant organic matter provides additional physiological information to distinguish the effects of stomatal conductance (as a proxy for water availability/air humidity) from the effects of changes in photosynthetic capacity (as a proxy for irradiance, temperature and nutrient availability) on $\delta^{13} \mathrm{C}$ (Farquhar et al. 1998, Scheidegger et al. 2000, Gessler et al. 2009b). This is because $\delta^{18} \mathrm{O}$ is modulated mainly by air humidity or more explicitly by the ratio $\left(e_{a} / e_{i}\right)$ of water vapour pressure in the atmosphere $\left(e_{a}\right)$ and leaf intercellular air space $\left(e_{\mathrm{i}}\right)$. As air humidity is a major driver for the variability of stomatal conductance, $\delta^{18} \mathrm{O}$ is affected by stomatal aperture (Gessler et al. 2009a) like $\delta^{13} \mathrm{C}$, but $\delta^{18} \mathrm{O}$ is not influenced by variations in photosynthesis (Barbour et al. 2000 , Scheidegger et al. 2000). The isotopic signal of evaporative enrichment of leaf water is imprinted with an equilibrium fractionation factor of $27 \%$ (Sternberg and DeNiro 1983, Cernusak et al. 2005) on the newly assimilated sugars and lastly in tree-ring organic matter.

The fractionation processes during evaporation and photosynthesis in leaves are reasonably well understood and can be described by mechanistic models (McCarroll and Loader 2004, Barbour 2007). Yet, it is increasingly recognized that post-carboxylation fractionation due to equilibrium and kinetic isotope effects in metabolic processes downstream from photosynthetic carboxylation are of importance for the isotope signals found in plant material (Gleixner et al. 1998, Schmidt 2003, Tcherkez and Farquhar 2005, Brandes et al. 2006, Bowling et al. 2008, Gessler et al. 2009a). In addition to the fractionation processes, the $\delta^{18} \mathrm{O}$ in tree rings is also influenced by the exchange of organic carbonyl oxygen atoms with reaction water. During cellulose synthesis and potentially also in upstream metabolic processes, some of the oxygen atoms of sucrose synthesized in the leaves are exchanged with trunk water, which is not evaporatively enriched and thus corresponds to source water (Sternberg et al. 1986, Farquhar et al. 1998, Roden and Ehleringer 1999, Sternberg 2009). Cernusak et al. (2005) reviewed the existing literature and concluded that the average exchange rate amounts to $\sim 42 \%$. However, Gessler et al. (2009a) showed that this exchange rate might not necessarily be constant over the growing season. The source water $\delta^{18} \mathrm{O}$ is normally close to the $\delta^{18} \mathrm{O}$ of precipitation, and the latter is often closely related to temperature and precipitation amount (Rozanski et al. 1992). As a consequence, it is extremely important for climate reconstruction to know how much of the oxygen isotopic signal in tree-ring organic matter directly originates from source water and which portion is altered by leaf-level processes.

During the last four decades studies about intra-annual isotope variations in tree rings have been published (Wilson and Grinsted 1975, Leavitt and Long 1991, White et al. 1994, Loader et al. 1995, Barbour et al. 2002, Helle and Schleser 2004, Klein et al. 2005, Gessler et al. 2009a, Ogee et al. 2009), and this approach has already shown its huge potential to better understand the link between leaf- and canopylevel physiology, climate information and tree-ring isotopic signature. High spatial resolution of isotopic signals within an annual growth ring, which translates into intra-annual temporal resolution, opens the possibility to compare leaf-level with tree-ring isotopic signals. As both $\delta^{13} \mathrm{C}$ and $\delta^{18} \mathrm{O}$ isotopic compositions are controlled by various and partially different environmental variables, several authors suggest simultaneous measurements of both isotope ratios (Saurer et al. 1997, Barbour et al. 2002, McCarroll and Loader 2004). However, the majority of existing high-resolution studies focus on one isotope only (e.g., Dawson et al. 2004, Helle and Schleser 2004, Klein et al. 2005).

Existing studies on both isotopes focus mainly on conifers and mostly do not include assessments of the fast-turnover sugar pools in leaves and/or phloem. Barbour et al. (2002) examined Pinus radiata D. Don. and found that specific events like droughts and periods with high temperature, vapour pressure deficit or rainfall were clearly recorded in the seasonal 
pattern of cellulose $\delta^{13} \mathrm{C}$ and $\delta^{18} \mathrm{O}$. Poussart et al. (2004) demonstrated seasonal patterns in $\delta^{18} \mathrm{O}$ and $\delta^{13} \mathrm{C}$ in Podocarpus wood, which does not produce well-defined growth rings. Roden et al. (2009) studied the intra-annual patterns of $\delta^{13} \mathrm{C}$ and $\delta^{18} \mathrm{O}$ in tree-ring cellulose to characterize the influence of fog on the water supply of Sequoia sempervirens. In the only study we are aware of where oxygen and carbon isotopic signals were tracked from the leaf via the phloem to the tree ring, Gessler et al. (2009a) reported seasonally variable $\delta^{13} \mathrm{C}$ enrichment of sugars during phloem transport and an uncoupling between tree-ring $\delta^{13} \mathrm{C}$ and leaf-level $c_{\mathrm{i}} / c_{a}$ in Pinus sylvestris $\mathrm{L}$. In contrast, the oxygen isotope signal was found to be transferred from the leaf water to the tree ring with the expected fractionation and a time lag of $\sim 2$ weeks.

In contrast to evergreen species, deciduous trees are likely to record environmental influences in the tree ring only at particular times during the growing season due to remobilization of photosynthates from the last growing season(s) in spring and to storage processes in autumn as shown by Helle and Schleser (2004) in beech. Kagawa et al. (2006a, 2006b) applied ${ }^{13} \mathrm{C}$ pulse labelling to show that early wood production of Larix gmelinii relies on both stored photoassimilates from the previous year and current assimilates. Helle and Schleser (2004) also demonstrated that only the $\delta^{13} \mathrm{C}$ signal in the early latewood and not in the earlywood encoded an environmental signal, but comparable studies to assess the effects of remobilization of stored carbohydrates on the $\delta^{18} \mathrm{O}$ of the tree ring are lacking.

With this study we sought to trace the fate of carbon and oxygen isotopes from inorganic sources (source water $\left(\delta^{18} \mathrm{O}\right)$ ) to the tree ring via fast turnover leaf water $\left(\delta^{18} \mathrm{O}\right)$, leaf organic matter $\left(\delta^{13} \mathrm{C}, \delta^{18} \mathrm{O}\right)$ and trunk phloem organic matter $\left(\delta^{13} \mathrm{C}\right.$, $\delta^{18} \mathrm{O}$ ), under varying environmental conditions during a whole growing season in the deciduous species Fagus sylvatica $L$. (European beech). We also related the isotope information to environmental variables such as air temperature $\left(T_{\mathrm{a}}\right)$, photosynthetic active radiation (PAR), vapour pressure (VP) and soil moisture (SM). Our central research questions were: Are the carbon and oxygen isotopic signatures imprinted on assimilates in the leaves during photosynthesis traceable in phloem organic matter and in the tree ring during the whole or during particular parts of the growing season? Are the responses of both isotopes in the tree ring and in other organic matter pools towards changes in environmental conditions and/or storage and remobilization correlated to each other during the whole growing season?

\section{Materials and methods}

\section{Experimental site}

The experimental site is located near Tuttlingen in southern Germany (longitude $8^{\circ} 45^{\prime} \mathrm{E}$; latitude: $47^{\circ} 59^{\prime} \mathrm{N}$ ) in the
Swabian Jura (740-760 $\mathrm{m}$ a.s.I.) on a steep NE exposed slope (58-100\%). The soil is characterized as Rendzic Leptosol derived from limestone (Weissjura beta and gamma series). The soil contains $15 \%$ rocks and stones in the upper $20 \mathrm{~cm}$, rising to a fraction of $30 \%$ below $50 \mathrm{~cm}$. European beech (F. sylvatica L.), aged 80-90 years, is the dominant species (fraction of total basal area $>90 \%$ ). The mean tree height is $\sim 28 \mathrm{~m}$ and the range of diameter at breast height (DBH) is between 10 and $42 \mathrm{~cm}$ ( $\mathrm{Nahm}$ et al. 2006). Further details on stand structure, soil and climatic conditions are described in Gessler et al. (2001), Nahm et al. (2006) and Holst et al. (2010).

The average annual $T_{\mathrm{a}}$ in 2007, measured $1.5 \mathrm{~m}$ above ground, was $7.0^{\circ} \mathrm{C}$, determined with a Humicap HMP45D sensor (Vaisala, Helsinki, Finland). The annual sum of precipitation amounted to $824 \mathrm{~mm}$, determined with a tipping bucket ARG 100 (Vaisala, Helsinki, Finland). Soil moisture at the field site was determined with two water content reflectometer probes (CS615, Campbell Scientific, Shepshed, UK) and is reported in vol\% soil water content as mean value from the upper $30 \mathrm{~cm}$ soil depth. Measured soil moisture profiles were compared regularly with gravimetric measurements of soil water content (Holst et al. 2010). Soil cores for the gravimetric approach were collected randomly from $0-30 \mathrm{~cm}$ depth on a $70 \times 70 \mathrm{~m}$ plot. Water vapour pressure of the air (VP) was measured in units of $\mathrm{hPa}$ at $1.5 \mathrm{~m}$ above ground level (a.g.l.) with a Humicap HMP45D sensor (Vaisala, Helsinki, Finland). Photon flux density (PFD) in the PAR wavelength region in $\mu \mathrm{mol} \mathrm{m} \mathrm{m}^{-2} \mathrm{~s}^{-1}$ (Li-190SZ, Li-COR Biosciences, Lincoln, NE, USA) was determined above the canopy at $36 \mathrm{~m}$ a.g.l. At the same height, wind speed was determined with a cup anemometer (WAA151, Vaisala, Helsinki, Finland). All measurements were aggregated from the raw data to half-hourly average values, which were used to calculate daily means.

\section{Canopy stomatal conductance and radial growth}

For the present study, transpiration was computed with the model DNDC (Li et al. 1992) as described in detail for the same stand by Holst et al. (2010). A comparison with transpiration data derived from xylem sap flow measurements showed good correlation between the two approaches $(R=0.98)$ for this beech stand. Mean canopy stomatal conductance $\left(G_{\mathrm{s}}\right)$ was calculated from the obtained transpiration rates using a simplified Penman-Monteith equation, as explained in detail by Keitel et al. (2003) for the same site.

Radial growth during the sampling period (4 April 2007 to 10 October 2007) was monitored on six trees divided into three DBH classes (DBH $<29.5 ; 29.5<\mathrm{DBH}<35.0 ; 35.0<\mathrm{DBH})$ with dendrometers (TypeDR, UP Umweltanalytische Produkte GmbH, Leipzig, Germany). 


\section{Collection of plant material, soil water and water vapour}

During the period between 4 April 2007 and 10 October 2007, phloem, leaf, xylem, atmospheric $\mathrm{CO}_{2}$, water vapour and soil samples were collected every 2 weeks. Sampling started between 10:30 and 11:15 $\mathrm{h}$ and ended between 12:10 and 13:30 h.

Phloem organic matter (OM) samples were randomly collected at breast height from the trunks of 10 beech trees, on each sampling day. We used the phloem exudation technique described in detail by Gessler et al. (2004). The authors of that paper showed that for carbon and oxygen isotope ratio analysis in phloem exudates, demineralized water was best suited as exudation solution, whereas for the quantification of transported sugars a chelating agent was necessary. The phloem exudation technique has been compared with other phloem sap extracting methods (phloem bleeding, Gessler et al. 2004; centrifugation, Devaux et al. 2009), and results for the stable isotope composition were comparable. Three different phloem exudates were obtained per tree, one for sugar analysis and two for isotope analysis. For all exudation approaches, bark pieces of $\sim 100 \mathrm{mg}$ fresh weight were collected as described by Gessler et al. (2004) at adjacent positions on the trunk of a given tree. Bark pieces were incubated in the exudation solutions; after $5 \mathrm{~h}$, the supernatant was decanted and stored in the freezer at $-20{ }^{\circ} \mathrm{C}$ and the weight of the bark piece was determined. For sugar analysis, bark pieces were incubated in $2 \mathrm{ml}$ of EDTA solution (10 mM). Previous studies with beech (Schneider et al. 1996) revealed that contamination of phloem exudates with cellular constituents was negligible under the experimental conditions applied here.

For isotope analysis, bark pieces were incubated in $2 \mathrm{ml}$ of demineralized water with two different $\delta^{18} \mathrm{O}$ isotopic signatures ( $\delta^{18} \mathrm{O}$ of depleted water: $-8.9 \pm 0.3 \%$; $\delta^{18} \mathrm{O}$ of enriched water: $8.9 \pm 2.5 \%$ o (mean values ( $\mathrm{MW} \pm$ standard deviation (SD); $n=10)$ ). Two different $\delta^{18} 0$ values were chosen to check for potential oxygen atom exchange between exuding phloem sugars and the exudation solution. The obtained oxygen isotope signatures of phloem organic matter did not differ between the two exudation solutions (mean phloem OM exuded in enriched water: $27.2 \pm 3.1 \%$ o $(n=110)$; mean phloem OM exuded in depleted water: $27.3 \pm 3.3 \%$ o $(n=111)$ (all values are $\mathrm{MW} \pm \mathrm{SD}$ )). We thus can exclude any significant oxygen atom exchange during the exudation procedure.

The exudation technique as a potential source for artefacts was additionally ruled out by comparing $\delta^{18} \mathrm{O}$ of phloem OM samples obtained with the exudation technique and from the phloem bleeding sap of eight trees, as previously described by Gessler et al. (2004). Although the SD of the bleeding sap samples was slightly higher (bleeding sap: $-29.0 \pm 1.4 \%$; exudation: $-29.4 \pm 0.8 \%$ o), a Student's $t$-test showed no significant difference between the mean values.
To obtain leaf water (LW), leaf total organic matter (LTOM), leaf water soluble organic matter (LWSOM) and xylem solution samples, twigs were collected from the sunlit canopy of five randomly chosen trees, representative for the whole stand. Five leaves per tree were selected for leaf water extraction, the major vein was removed and the leaves were transferred into a Duran ${ }^{\circledR}$ (DURAN GmbH, Mainz, Germany) culture tube immediately. For xylem samples, a twig piece of $\sim 10 \mathrm{~cm}$ length and $1.5 \mathrm{~cm}$ diameter was taken. After the bark was removed, it was transferred in a Duran ${ }^{\circledR}$ tube. For leaf organic matter analyses, five additional leaves were harvested from each twig. All samples were immediately stored on dry ice and kept at $-80^{\circ} \mathrm{C}$ until further analysis.

Atmospheric water vapour for $\delta^{18} \mathrm{O}$ measurements was collected from two different heights (mid canopy, $\sim 15 \mathrm{~m}$, and top canopy, $\sim 30 \mathrm{~m}$ ). Starting at about 12:00 h, the air was drawn for 1-2 $\mathrm{h}$ through two successive $U$-tubes that were cooled by an ethanol-dry ice mixture to $\sim-70^{\circ} \mathrm{C}$ to trap the water vapour (Ferrio et al. 2009).

Soil water extraction samples were collected from three randomly chosen places at depths of $1-2 \mathrm{~cm}$ (upper) and 10-12 cm (lower), and then placed in a Duran ${ }^{\circledR}$ tube. The soil samples were stored on dry ice at $-80^{\circ} \mathrm{C}$ until further analysis.

Tree core samples for the intra-annual measurements of $\delta^{13} \mathrm{C}$ and $\delta^{18} \mathrm{O}$ in whole wood were taken on 18 April 2008, before the new growth started (about 3 May 2008) with a $5 \mathrm{~mm}$ core increment borer (Suunto, Vantaa, Finland). We took six cores from four different trees at breast height. Three trees were sampled once (the cores named TC2, TC3, TC4), taking the core from the south-east side of the trunk, parallel to the slope. One tree was sampled three times. The first core (TC1a) was taken from the SE side as well, while the following were sampled in an angle of $180^{\circ}$ (TC1c) and $90^{\circ}$ (TC1d) from the previous core.

\section{Sample processing}

Leaf total organic matter samples were dried at $60^{\circ} \mathrm{C}$ in a drying oven. The dried plant material was ground with a ball mill to obtain a homogeneous powder. For LTOM samples, $0.3-1.0 \mathrm{mg}$ of the ground material was weighed into tin and silver capsules for carbon and oxygen isotope analysis, respectively. To obtain the LWSOM fraction, $1 \mathrm{ml}$ of deionized water was added to 45-55 mg of homogenized sample material. After $1 \mathrm{~h}$ of agitation at $4^{\circ} \mathrm{C}$, samples were heated for $10 \mathrm{~min}$ at $95^{\circ} \mathrm{C}$, cooled down to room temperature and centrifuged (10 min, 12,000 g) to remove soluble proteins. The pellet was discarded and the supernatant (LWSOM), which is representative for the mixture of sugars, organic acids and amino acids with high turnover rates (Brandes et al. 2006), was used for isotope analysis. For carbon isotope analysis, $0.1 \mathrm{ml}$ of the supernatant was transferred into pre-weighed tin capsules (IVA Analysetechnik, 
Meerbusch, Germany) and the same volume was transferred into pre-weighed silver capsules for oxygen isotope analysis (IVA Analysetechnik, Meerbusch, Germany). Before analysis, the water from the capsules was evaporated at $60^{\circ} \mathrm{C}$ in a drying oven so that only the soluble organic matter remained.

The concentration of fructose, glucose and sucrose in the supernatant of the EDTA containing phloem exudation solutions was analysed with high-performance liquid chromatography (HPLC; DX 500; Dionex, Idstein, Germany). Aliquots (200 $\mu \mathrm{l})$ of the sample were diluted with 500 I of double deionized water. From this mixture, $100 \mu \mathrm{l}$ was injected into the HPLC system. For separation of the sugars, a CarboPac PA1 separation column $(4 \times 250 \mathrm{~mm}$; Dionex $\mathrm{GmbH}$, Idstein, Germany) with a $\mathrm{NaOH}$-water gradient $\left(\mathrm{NaOH} 200 \mathrm{mmol} \mathrm{I}^{-1}\right)$ as eluent and a flow rate of $1 \mathrm{ml} \mathrm{min}^{-1}$ was used. Sugars were identified and quantified with external standards. The sugar concentrations were expressed in moles of sugar $C$ per gram of bark.

Of the supernatant from the exudation solutions with demineralized water for isotope analyses, $200 \mu$ l was transferred into silver capsules for oxygen analysis. The same sample volume in tin capsules was used for carbon analysis. Before the mass spectrometer analysis, water was evaporated at $60^{\circ} \mathrm{C}$ in a drying oven.

Xylem, soil and leaf water samples were extracted by cryogenic vacuum distillation (Ehleringer et al. 2000; for a detailed description, see Brandes et al. 2007). The frozen samples were placed in an $80{ }^{\circ} \mathrm{C}$ water bath and connected to a vacuum system. Samples were heated and, by applying a vacuum of $\sim 4 \times 10^{-2}$ mbar, were transferred to water traps that were cooled with liquid nitrogen. The water was transferred into $1.5 \mathrm{ml}$ glass vials (IVA Analysetechnik, Meerbusch, Germany), and then the vials were sealed and stored at $4{ }^{\circ} \mathrm{C}$ until analysis.

\section{Intra-annual dating of tree rings and processing of tree-ring organic matter}

To obtain an average estimate of the tree-ring increment in 2007, we used dendrometer data from six trees. To avoid problems due to variations in the absolute increment between single trees, we transformed the values to a relative scale from 0 to 1 . The average curve obtained from the six trees was then smoothed (see the Statistics section). The width of the 2007 year rings, ranging from 0.9 to $1.7 \mathrm{~mm}$, was measured by scanning pictures of the tree cores and measuring the width (number of pixels) at six different positions. The date-growth relation was obtained by assigning the width of the year ring to the relative increment curve.

The tree rings were cut in to $40 \mu \mathrm{m}$ slices with a microtome (Mod. 1206 with Frigomobil, cooling device Reichert-Jung; Leimen, Germany), comprising 1-17 days on the time scale (isotope values for each measured slice are shown in the supplementary material: Figures $\mathrm{S} 1$ and $\mathrm{S} 2$ available as
Supplementary Data at Tree Physiology Online). Aliquots of $\sim 0.5 \mathrm{mg}$ of whole wood were transferred to tin and silver capsules for carbon and oxygen isotope analyses, respectively. Data gaps in the tree core data were filled with the mean value of the adjacent $\delta^{13} \mathrm{C}$ and $\delta^{18} \mathrm{O}$ values and the data were smoothed with a spline function to obtain an estimated daily value for the tree-ring wood.

Differences in growth patterns among individual trees lead to uncertainties in dating of the tree slice as well as errors in determining the extent of an annual tree ring. Therefore, as a quality control of the intra-annual chronology, we studied the inter-correlation of the isotope values assigned to each day of the year for the different tree cores using a freeware software commonly used in dendrochronology (COFECHA, Tree-Ring Lab and Columbia University; Holmes 1983). Originally developed to match tree-ring width patterns for cross-dating, Roden (2008) also applied COFECHA for cross-dating inter-annual tree ring $\delta^{18} \mathrm{O}$ and $\delta^{13} \mathrm{C}$ time series. In our case, we applied COFECHA to the intra-annual isotope chronologies obtained after assigning a date to each tree slice. They were assessed without applying any detrending or autoregressive models, and using segments of 50 days lagged successively by 25 days. Inter-correlations between segments of tree-ring series, using different time lags, were applied to detect potential dating errors. This information was complemented with the correlation of each individual series (tree core) with an adjusted master series (i.e., removing the contribution of the tested series; see Grissino-Mayer 2001 for details). It should be noted that, given that the number of time divisions per tree slice was variable among trees and along time, the statistics derived from assigned daily values were only used qualitatively, in order to assist in detecting potential dating problems.

\section{Isotope ratio mass spectrometry}

For $\delta^{13} \mathrm{C}$ analysis, samples were combusted in an elemental analyser (NA 2500; CE Instruments, Milan, Italy), and for $\delta^{18} \mathrm{O}$ analysis in a high-temperature conversion/elemental analyser (TC/EA; Finnigan MAT GmbH, Bremen, Germany), both coupled to an isotope ratio mass spectrometer (Delta Plus or Delta Plus XP, Finnigan MAT GmbH, Bremen, Germany) by a Conflo ॥ interface (Finningan MAT GmbH, Bremen, Germany). Carbon isotopic values were expressed in $\delta$ notation, relative to the Vienna Pee Dee Belemnite (VPDB) standard. For oxygen, $\delta$ notation relative to the Vienna Standard Mean Ocean Water (VSMOW) was used. In order to avoid absorption of water vapour to the dried organic matter sample material and thus an artificial alteration of the $\delta^{18} \mathrm{O}$ value (Cernusak et al. 2003, Brandes et al. 2007), we shielded all organic matter samples under an argon atmosphere and kept the autosampler of the TC/EA flushed with dry argon. The precision for measurements of both isotopes as determined by repeated measurements of standards $(n=10)$ was better than $0.1 \%$. 


\section{Isotope calculations}

To eliminate variations in the oxygen isotope composition $\left(\delta^{18} \mathrm{O}\right)$ due to variations in the isotopic composition of source water, the enrichment above source water $\left(\Delta^{18} \mathrm{O}\right)$ can be calculated as follows:

$$
\Delta^{18} \mathrm{O}=\frac{\delta^{18} \mathrm{O}_{\text {sample }}-\delta^{18} \mathrm{O}_{\text {source }}}{1+\delta^{18} \mathrm{O}_{\text {source }}}
$$

with the measured $\delta^{18} \mathrm{O}$ value of the sample $\left(\delta^{18} \mathrm{O}_{\text {sample }}\right)$ and the measured $\delta^{18} \mathrm{O}$ value of the source water $\left(\delta^{18} \mathrm{O}_{\text {source }}\right)$. We used xylem as source water for the calculation of $\Delta^{18} \mathrm{O}$.

We applied evaporative ${ }^{18} \mathrm{O}$ enrichment models to compare predicted values with measured leaf water enrichment in order to explore the mechanistic basis of seasonal variations in $\delta^{18} \mathrm{O}$. The general procedures are given in detail by Farquhar and Cernusak (2005) and Barnard et al. (2007). In brief, steadystate enrichment at the sites of evaporation $\left(\Delta^{18} \mathrm{O}_{\mathrm{e}}\right)$ in the leaves was calculated according to the equation from Craig and Gordon (1965) modified by Dongmann et al. (1974). We took into account the oxygen isotopic difference between water vapour in the atmosphere and source water, the ratio of ambient to intercellular water vapour concentration, the equilibrium fractionation between liquid water and water vapour and the kinetic isotope fractionation during water vapour diffusion as depending on stomatal and boundary layer conductance. Average lamina mesophyll water is supposed to be less enriched than the water at the evaporative sites. This difference mainly depends on (i) the diffusion of ${ }^{18} \mathrm{O}$-enriched water away from the sites of evaporation and (ii) the convection of unenriched xylem water via the transpiration stream in the opposite direction (Péclet effect). Steady state enrichment of mean lamina leaf water $\left(\Delta^{18} \mathrm{O}_{\mathrm{L}}\right)$ depends on the steadystate enrichment at the evaporative site of the leaf $\left(\Delta^{18} \mathrm{O}_{\mathrm{e}}\right)$ and on the lamina radial Péclet number $\wp$ (Farquhar and Lloyd 1993). $\wp$ depends on the leaf transpiration rate $\left(\mathrm{mol} \mathrm{m}^{-2} \mathrm{~s}^{-1}\right)$, on a scaled effective pathlength $L$ assumed to be $0.015 \mathrm{~m}$ on average for beech leaves at that site (Keitel et al. 2006), the molar concentration of water and the diffusivity of $\mathrm{H}_{2}{ }^{18} \mathrm{O}$ in water (Barbour et al. 2000).

Modelling of leaf water enrichment was based on the following assumptions of Keitel et al. (2006) and Brandes et al. (2007): the difference between air temperature and leaf temperature can be calculated according to a leaf energy balance model described in detail by Barbour et al. (2000) and Cernusak et al. (2003). Isothermal net radiation as an input parameter for the energy balance model was estimated as described by Barbour et al. (2000), with the global radiation values measured above the canopy. Internal water vapour $e_{\mathrm{i}}$ was assumed to be equal to the leaf-temperature-dependent saturation pressure. Boundary layer resistance for sun crown leaves, based on estimates from wind velocity above the canopy and from leaf length (Jones 1992), and canopy stomatal conductance were used to calculate kinetic isotope fractionation. Stand transpiration was calculated from the model DNDC, and average canopy leaf transpiration, necessary for calculating $\wp$, was computed taking into account an leaf area index of $5.2 \mathrm{~m}^{2} \mathrm{~m}^{-2}$ (Holst et al. 2004). $\Delta^{18} \mathrm{O}$ of atmospheric water vapour for a given day was calculated as mean value of the samples taken from 15 and $30 \mathrm{~m}$ height.

To estimate the proportion of oxygen atoms, which potentially exchange ( $p_{\mathrm{ex}}^{\text {phloem }}$ ) on the way from leaf sugars to the stem phloem with unenriched source (i.e., xylem) water, we applied the following equation:

$$
p_{\mathrm{ex}}^{\text {phloem }}=\frac{\delta^{18} \mathrm{O}_{\text {WSOM }}-\delta^{18} \mathrm{O}_{\text {phloemOM }}}{\delta^{18} \mathrm{O}_{\text {WSOM }}-\left(\delta^{18} \mathrm{O}_{\text {xylem }}+\varepsilon_{\mathrm{wc}}\right)}
$$

where $\varepsilon_{\mathrm{wc}}$ is the average equilibrium fractionation between carbonyl oxygen and water (27\%o). $\delta^{18} \mathrm{O}_{x y l e m}$ denotes the oxygen isotope signature of xylem water (assumed to equal the unenriched source water in the trunk), $\delta^{18} \mathrm{O}_{\text {phloemom }}$ the oxygen isotope signature of phloem OM and $\delta^{18} \mathrm{O}_{\text {LWSOM }}$ that of LWSOM.

\section{Statistics}

All statistical analyses were performed with $R$ ( $R$ Development Team 2008). Pearson's correlation coefficients were calculated with the 'cor' function. Significance of the correlations was tested with the 'cor.test' function. To avoid alpha error accumulation due to multiple testing (i.e., wrongly assume results to be significant), we applied in addition the Bonferroni-Holm correction (Holm 1979). Smoothing of the data was performed with a loess fit with span $=0.4$ or the 'smooth.spline' function, with the generalized cross-validation method.

\section{Results}

\section{Meteorological conditions and stomatal conductance}

During the sampling period (day of year (DOY) 124-283 in 2007), daily mean temperature was generally $>5^{\circ} \mathrm{C}$ (Figure 1a). Maximum $\left(24^{\circ} \mathrm{C}\right)$ and minimum $\left(-1{ }^{\circ} \mathrm{C}\right) T_{\mathrm{a}}$ values were reached in July and October, respectively. The minimum VP was reached in October with $5 \mathrm{hPa}$. Maximum VP amounted to $18 \mathrm{hPa}$ in July when the highest PFD values were also observed (Figure 1b). In 2007, soil moisture had its highest and lowest values in the first part of the growing season. Maximum values of up to $61 \%$ were observed in early April and soil moisture dropped to $\sim 36 \%$ at the end of May and in mid June. $G_{\mathrm{s}}$ showed on average lowest values in July (Figure 1c). As already stated by Brandes et al. (2006), the inverted Penman-Monteith equation used for computing $G_{s}$ yields unrealistically high values at relative humidity $(\mathrm{rH})$ values exceeding $90 \%$. All $G_{\mathrm{s}}$ values exceeding $200 \mathrm{mmol} \mathrm{m}^{-2} \mathrm{~s}^{-2}$ occurred on days with $\mathrm{rH}>90 \%$. 
DOY

(a)

(b)

(c)

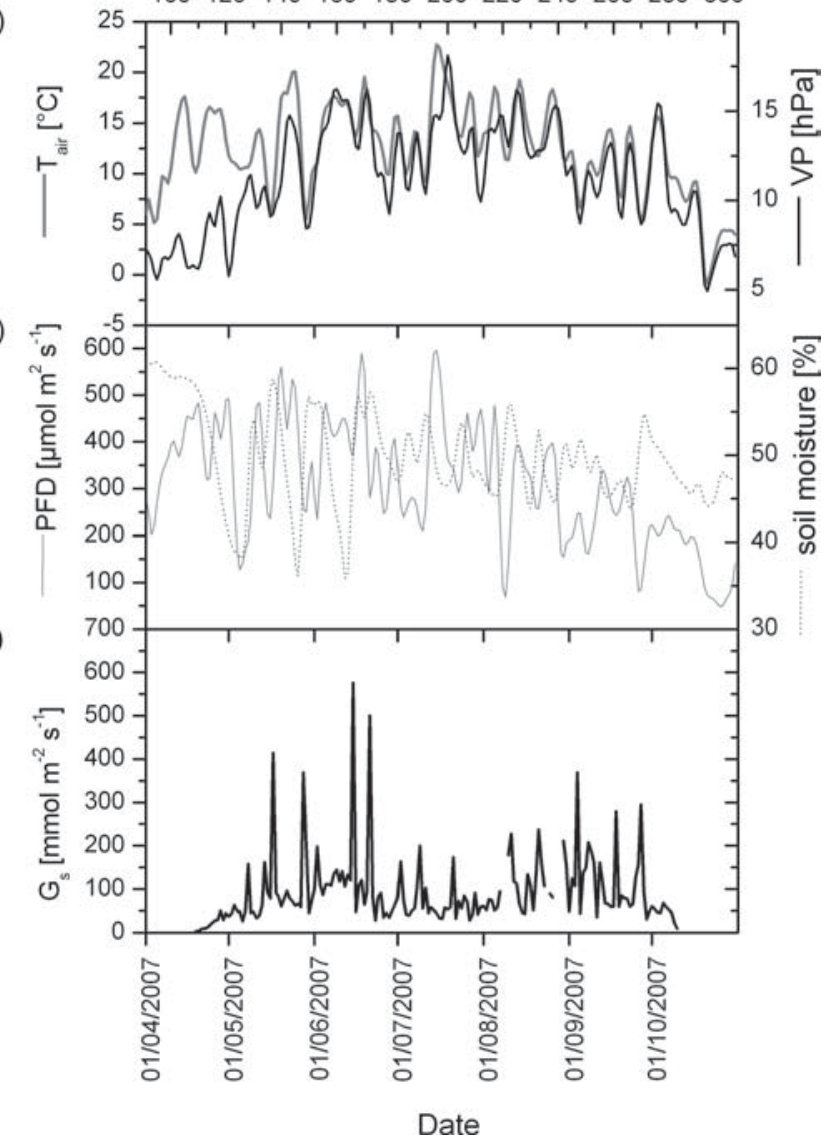

Figure 1. Meteorological conditions (a, b) and canopy stomatal conductance (c) during the sampling period. (a) Air temperature $\left(T_{\mathrm{a}}\right)$ in ${ }^{\circ} \mathrm{C}$ at $1.5 \mathrm{~m}$ a.g.l. and water vapour pressure (VP) in $\mathrm{hPa}$ at $1.5 \mathrm{~m}$ a.g.l. (b) Soil moisture as mean value from the upper $30 \mathrm{~cm}$ depth and photon flux density (PFD) in the PAR wavelength region in $\mu \mathrm{mol} \mathrm{m} \mathrm{m}^{-2} \mathrm{~s}^{-2}$ at $36 \mathrm{~m}$ a.g.l. (above the canopy) in $\mu \mathrm{mol} \mathrm{m}^{-2} \mathrm{~s}^{-1}$. (c) Canopy stomatal conductance in mmol m $\mathrm{m}^{-2} \mathrm{~s}^{-1}$. The meteorological data are smoothed with a spline interpolation.

\section{Tree core dating}

According to the dendrometer data, radial growth occurred from day 123 to day 232 (DOY). Quality control of intraannual dating of tree slices using COFECHA indicated that inter-tree correlations of assigned daily values were stronger for $\delta^{18} \mathrm{O}$ than for $\delta^{13} \mathrm{C}$ (average correlation with the master series: $r=0.564$ and $r=0.219$, respectively). In general, 50 -day segment correlations were best with the original dating. Only in core TC1d the correlation for $\delta^{13} \mathrm{C}$ improved by slightly redating the core (best correlation: with a lag of -4 from day 150 to 230 , and with a lag of +1 from day 123 to 175). Accordingly, we re-scaled the segment between day 150 and 175 for this core to fit with these dates, in a way that former days 123-150 became days 124-151 (lag $=+1)$, and days $175-230$ became days $171-226(\operatorname{lag}=-4)$. This increased the correlation between $\delta^{13} \mathrm{C}$ of core TC1d and the master series from $r=0.383$ to $r=0.529$ (new average correlation with master series: $r=0.245)$. These changes had only small effects in the $\delta^{18} \mathrm{O}$ chronology $(r=0.538)$. Average correlations were still low due to the lack of correlation of core TC1a with the master series $(r=-0.064)$. This core was also not correlated with the others for $\delta^{18} \mathrm{O}$ $(r=-0.080)$, and showed some clear outlier values for $\delta^{18} \mathrm{O}$, suggesting the presence of tension/compression wood, wounds or other kinds of contamination. After excluding this core, the average correlation with the master series increased for both $\delta^{13} \mathrm{C}$ and $\delta^{18} \mathrm{O}(r=0.339$ and $r=0.612$, respectively). Consequently, the latter chronology (i.e., redating core TC1d and excluding core TC1a) was used in all subsequent calculations.

\section{Carbon isotope signatures: leaf carbon pools, trunk phloem, tree-ring whole wood}

In the leaves, seasonal patterns of LWSOM were comparable to LTOM from June until the end of the growing season (Figure 2a). In contrast, in spring from day of year (DOY) 124 until DOY $151 \delta^{13} \mathrm{C}$ of LWSOM decreased from a level comparable to phloem organic matter (-29.7\%o phloem, $-29.6 \%$ oWSOM) to values in the range of LTOM. Exactly during the same time period, phloem sugar concentrations increased from 35 to $218 \mu \mathrm{mol}$ sugar $\mathrm{C}(\mathrm{g} \text { bark) })^{-1}$, presumably indicating increased sugar transport. This maximum value was more or less constant until the end of the growing season (Figure 2b). A comparison between $\delta^{13} \mathrm{C}$ of LTOM/LWSOM and phloem organic matter reveals an increasing difference during the first month of the growing season and a more or less constant difference between DOY 151 and 235. As a consequence, $\delta^{13} \mathrm{C}$ of LWSOM and phloem organic matter were highly correlated between June and August $(r=0.94, P=0.006)$. After DOY 235 (the end of radial growth) until the end of the growing season, the difference in $\delta^{13} \mathrm{C}$ between leaf and phloem organic matter increased further. At the last sampling in October, phloem OM was enriched by $3.1 \%$ o compared with LWSOM. These patterns over the whole growing season resulted in the overall low correlations in $\delta^{13} \mathrm{C}$ between phloem and the different leaf organic matter pools (Table 1).

$\delta^{13} \mathrm{C}$ in the whole wood of the tree rings differed among trees but also within one given tree (Figure S1). The cores TC1c and TC1d taken from one tree differed on average by $2.3 \%$ during the growing season. Average $\delta^{13} \mathrm{C}$ values of the four measured trees decreased slightly from the beginning of the growing season $(-28.86 \pm 1.42 \%$ o at the beginning of May) to autumn $(-29.42 \pm 1.44 \%$ o at the end of the trunk growth period) (Figure 2c). The maximum difference in $\delta^{13} \mathrm{C}$ between spring maximum and late summer/autumn minimum was $1.5 \%$. There was a clear common seasonal trend in $\delta^{13} \mathrm{C}$ of LTOM and treering wood to decrease by $>1 \%$ ofrom spring to autumn, leading to a highly significant correlation (Table 1). A comparable trend 


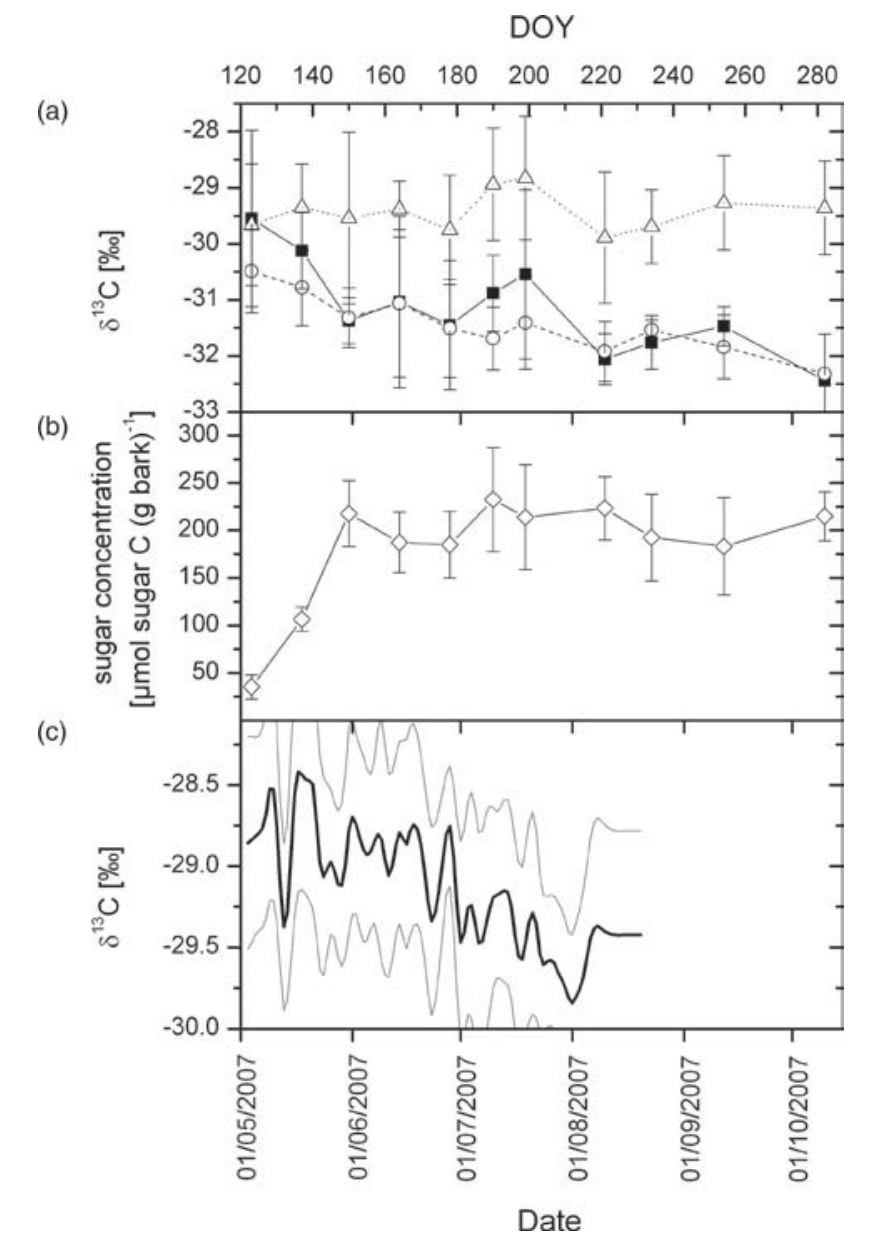

Figure 2. Carbon isotope composition $\left(\delta^{13} \mathrm{C}\right)$ of different tissues and phloem sugar concentration. (a) $\delta^{13} \mathrm{C}$ of leaf water soluble organic matter (LWSOM, black squares) and leaf total organic matter (LTOM, white circles) and phloem OM (white triangles), (b) sugar concentration in the trunk phloem and (c) average $\delta^{13} \mathrm{C}$ in the whole wood of tree rings over the growing season 2007. In (c) the cross-dated $\delta^{13} \mathrm{C}$ data from all trees were averaged and smoothed with a spline. Error bars in (a) and (b) indicate standard deviations and the grey lines in (c) are the standard errors of means. and a significant correlation with $\delta^{13} \mathrm{C}$ of wood were also observed for LWSOM but not phloem organic matter.

With phloem sugar concentration and trunk growth as indicators for major changes in physiological processes over the year, we can distinguish three phases of carbon allocation during the growing season in which different $\delta^{13} \mathrm{C}$ patterns are apparent.

Phase 1: Spring increase of phloem sugar transport. During this phase leaves increased their source strength, indicated by the increasing deviation between $\delta^{13} \mathrm{C}$ of LWSOM and of phloem OM. Phase 2: Constant phloem sugar concentration during continuing wood formation indicates neither carbon source nor sink strength changes. Leaf water soluble organic matter and phloem $\delta^{13} \mathrm{C}$ show highly significant correlation and a rather constant difference of $1.8 \pm 0.2 \%$ o during this time. Phase 3: Wood formation has stopped but carbon production is still going on albeit decreasing. The gap between leaf and phloem $\delta^{13} \mathrm{C}$ values widens further.

\section{Oxygen isotope signatures: water and organic matter pools}

During the growing season, soil water $\delta^{18} \mathrm{O}$ showed a maximum variation of $4.7 \%$ in the upper $(1-2 \mathrm{~cm})$ and $5.0 \%$ in the lower $(10-12 \mathrm{~cm}$ ) sampling depth (Figure 3a). On most sampling days, soil water from the top layer was slightly enriched compared with the bottom layer, with differences ranging between $5.9 \%$ and $-0.1 \%$. With the exception of the first sampling day, soil water values showed highest enrichment during the summer. The relatively high enrichment in the top layer at the first sampling day coincides with a relatively low soil moisture value of $38 \%$ for that day (Figure 1).

$\delta^{18} \mathrm{O}$ in xylem water showed a seasonal pattern comparable to soil water. In September and October when soil water $\delta^{18} \mathrm{O}$ started to decrease, xylem water in contrast stayed constant.

Measured leaf water $\delta^{18} \mathrm{O}$ showed strong variations over the growing season, ranging between $+7.6 \%$ and $-9.0 \%$. The

Table 1. Correlation of $\mathrm{C}$ and $\mathrm{O}$ isotope signatures of different tree organic matter pools and in leaf, xylem and soil water.

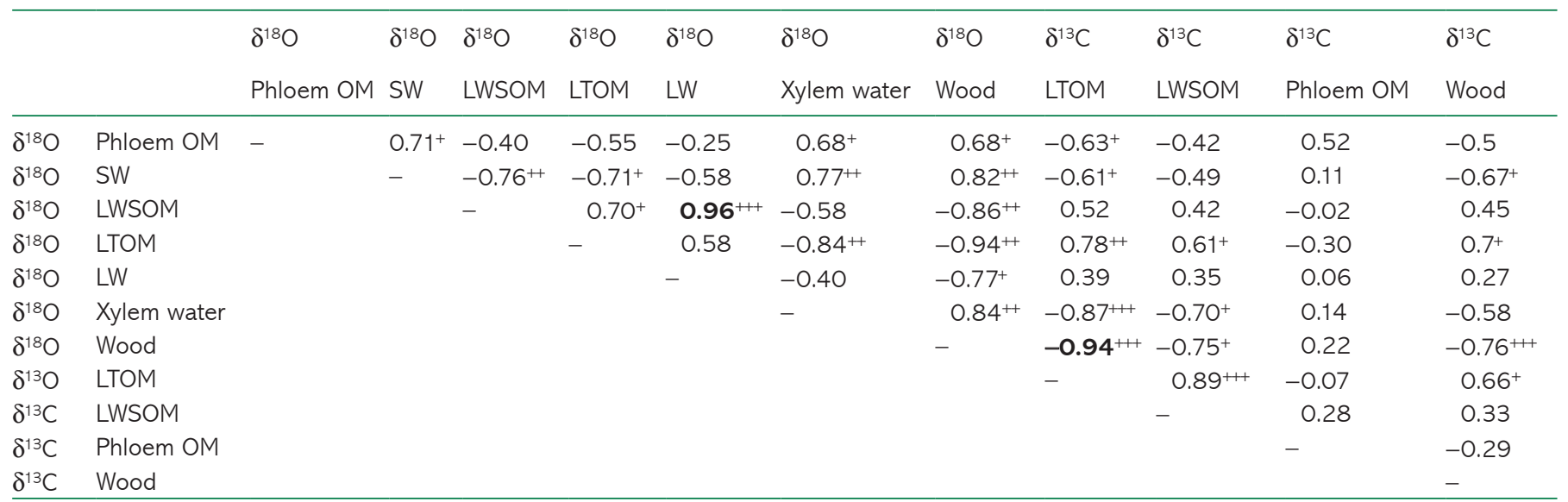

The significance levels for Pearson's correlation coefficients displayed are denoted as follows: $P<0.05=+; P<0.01=++; P<0.001=++$.

Bold figures indicate a significance level $P<0.05$ after Bonferroni-Holm correction. SW, soil water; LWSOM, leaf water soluble organic matter; LTOM, leaf total organic matter; LW, leaf water. 


\section{DOY}

(a)

(b)

(c)

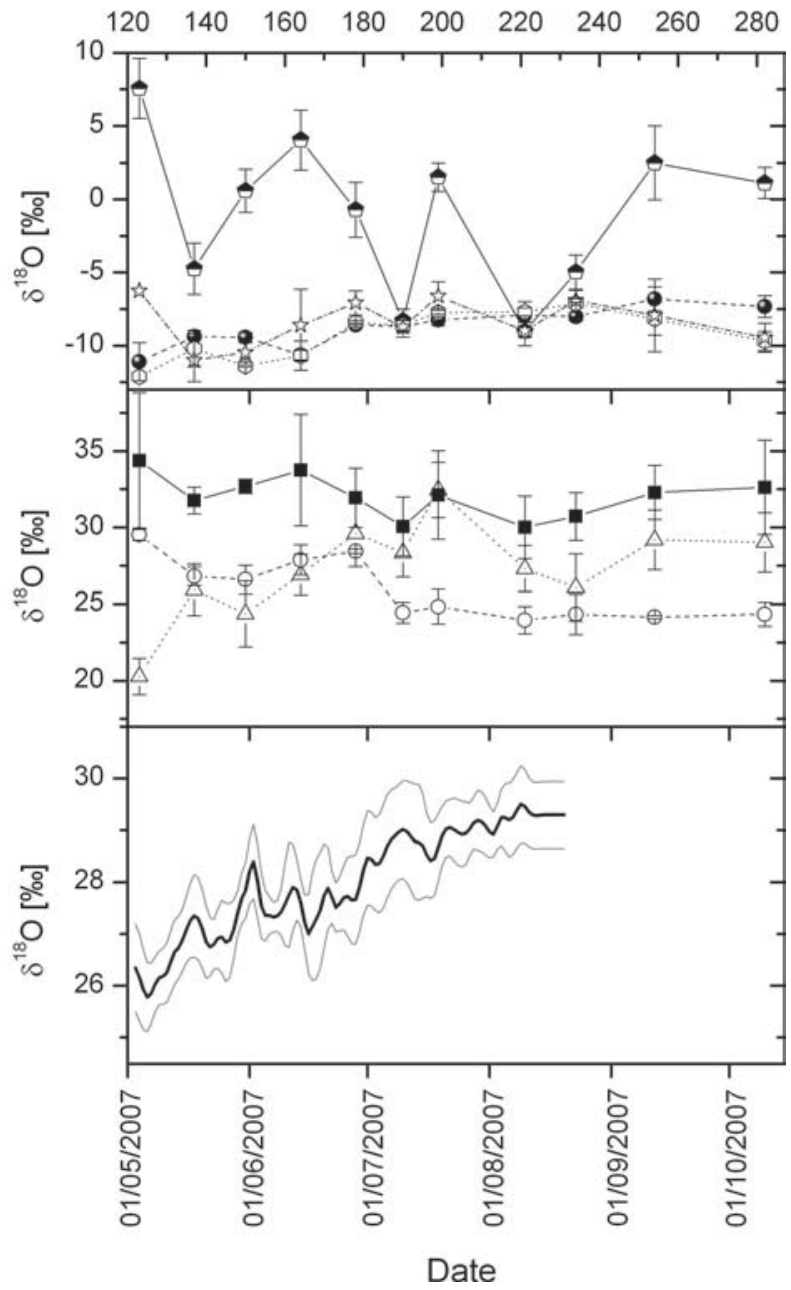

Figure 3. Oxygen isotope composition $\left(\delta^{18} \mathrm{O}\right)$ of different water pools and organic matter pools. (a) $\delta^{18} \mathrm{O}$ of leaf (black-white diamond), xylem (black circle) and soil water $(0-2 \mathrm{~cm}$ : star; $10-12 \mathrm{~cm}$ : white hexagon), (b) $\delta^{18} \mathrm{O}$ of leaf (LWSOM, black squares; LTOM, white circles) and phloem organic matter (white triangles) and (c) $\delta^{18} \mathrm{O}$ in the whole wood of tree rings over the growing season 2007. In (c) the cross-dated $\delta^{18} \mathrm{O}$ data from all trees were averaged and smoothed with a spline. Error bars in (a) and (b) indicate standard deviations and the grey lines in (c) the standard error of means.

fluctuations of leaf water $\delta^{18} \mathrm{O}$ were mirrored by LWSOM and LTOM, but, with a dampening of the amplitude (Figure 3b). Both LWSOM and LTOM showed a similar pattern throughout the growing season, with generally higher $\delta^{18} \mathrm{O}$ values in LWSOM.

$\delta^{18} \mathrm{O}$ in phloem OM increased-in contrast to leaf OM and leaf water-from spring until July and followed the leaf water $\delta^{18} \mathrm{O}$ pattern only from July to October.

Finally, $\delta^{18} \mathrm{O}$ in the whole wood of the tree rings showed-as observed for $\delta^{13} \mathrm{C}$ - strong variations among individual trees (Figure S2). The average $\delta^{18} \mathrm{O}$ value of the four trees showed a clear increase during the growing season starting from $26.3 \%$ 。 in May and reaching $29.3 \%$ in September (Figure 3c). $\delta^{18} \mathrm{O}$ of wood was positively correlated with phloem organic matter
(Table 1). The negative correlation coefficient for correlation between $\delta^{18} \mathrm{O}$ of wood and $\delta^{18} \mathrm{O}$ of LTOM and LWSOM indicates opposite seasonal courses.

In order to mechanistically assess the environmental and physiological factors driving the seasonal variation in leaf water $\delta^{18} \mathrm{O}$, we calculated the ${ }^{18} \mathrm{O}$ enrichment relative to source water (i.e., xylem) $\left(\Delta^{18} \mathrm{O}\right)$ and compared these observed $\Delta^{18} \mathrm{O}$ values with the values computed for average lamina leaf water by an evaporative ${ }^{18} \mathrm{O}$ enrichment model, which takes into account kinetic and equilibrium fractionation, isotopic differences between source water and the atmosphere, and the Péclet effect. The model described the seasonal patterns of leaf water enrichment reasonably well (Figure 4a), and the correlation analysis between measured and modelled values resulted in $r=0.87(P<0.01)$. The $\delta^{18} \mathrm{O}$ isotope signal of leaf water was strongly imprinted on LWSOM, as indicated by a correlation coefficient of 0.96 (Table 1). Phloem $\delta^{18} \mathrm{O}$ showed negative correlation to leaf water and LWSOM $\delta^{18} \mathrm{O}$ and seemed to be strongly influenced by soil (and xylem) water $\delta^{18} \mathrm{O}$ (Table 1).

Based on the positive correlation between soil or xylem water $\delta^{18} \mathrm{O}$ and phloem $\mathrm{OM} \delta^{18} \mathrm{O}$ and the lack of such a relation with LWSOM, we might assume that an exchange of oxygen atoms between phloem-transported sugars and the surrounding non-enriched xylem water took place. To account for this, we calculated the oxygen atom exchange $\left(p_{\mathrm{ex}}^{\text {phloem }}\right)$ from the isotope oxygen composition of LWSOM (assuming leaf organic matter to be the only source of phloem-transported sugars), phloem OM and xylem water (Figure 4b). The calculated oxygen exchange rate was highly variable throughout the growing season, with values decreasing from 0.76 to $\sim 0$ between May and July. Towards the end of the growing season and after stem growth had ceased, $p_{\mathrm{ex}}^{\text {phloem }}$ increased to values between 0.2 and 0.4 .

\section{Correlation between $\delta^{13} \mathrm{C}$ and $\delta^{18} \mathrm{O}$}

There was a significant, positive correlation between $\delta^{18} \mathrm{O}$ and $\delta^{13} \mathrm{C}$ in LTOM (Table 1), while wood $\delta^{18} \mathrm{O}$ and $\delta^{13} \mathrm{C}$ signatures were highly negatively correlated $(r=-0.76, P<0.001)$ for the whole growing season (Figure 5$)$. The correlation slightly increased $(r=-0.77 ; P<0.001)$ when only the time period of trunk growth and full sugar export in the phloem (phase 2; 31 May to 10 August 2007 (DOY 151-222)) was considered.

\section{Relation of the isotopic composition of plant organic matter pools to meteorological parameters}

Leaf water and LWSOM $\delta^{18} \mathrm{O}$ were highly (negatively) correlated with $\mathrm{rH}(r=-0.79$ and -0.75 , respectively; $P<0.01)$. There was a weaker, albeit significant, correlation between $\mathrm{rH}$ and $\delta^{18} \mathrm{O}$ in LTOM $(r=-0.69, P<0.05)$. Moreover, $\delta^{18} \mathrm{O}$ of leaf water and LWSOM were significantly correlated with volumetric soil water content ( $r=0.78$ and 0.67 , respectively). There was, 
(a)

(b)

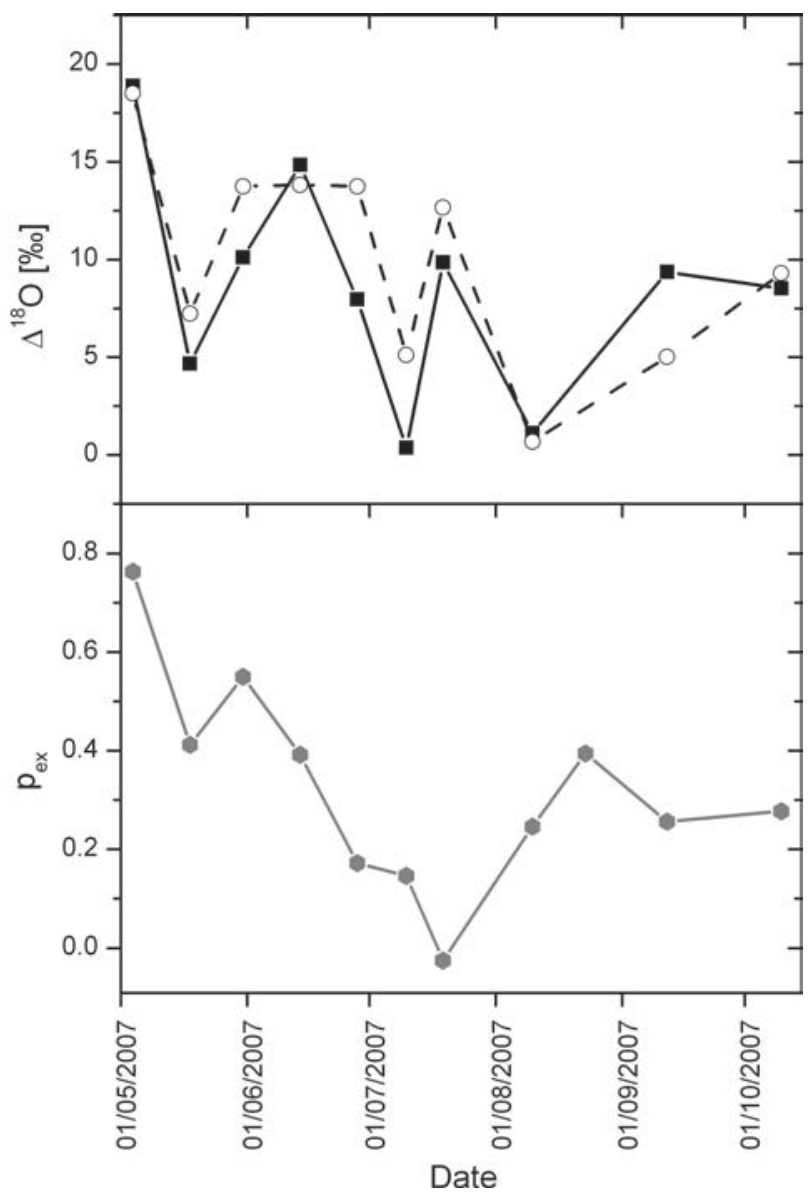

Figure 4. ${ }^{18} \mathrm{O}$ enrichment in leaf water (a) and the rate of exchange between organic oxygen and the non-enriched trunk water in phloem OM (b). (a) compares the observed ${ }^{18} \mathrm{O}$ enrichment (black squares) with modelled values (white circles), taking into account the Péclet effect. In (b) the oxygen exchange rate $p_{\mathrm{ex}}$ of phloem OM was calculated from the oxygen isotope composition of LWSOM (assuming leaf organic matter to be the only source of phloem-transported sugars) phloem OM and xylem water.

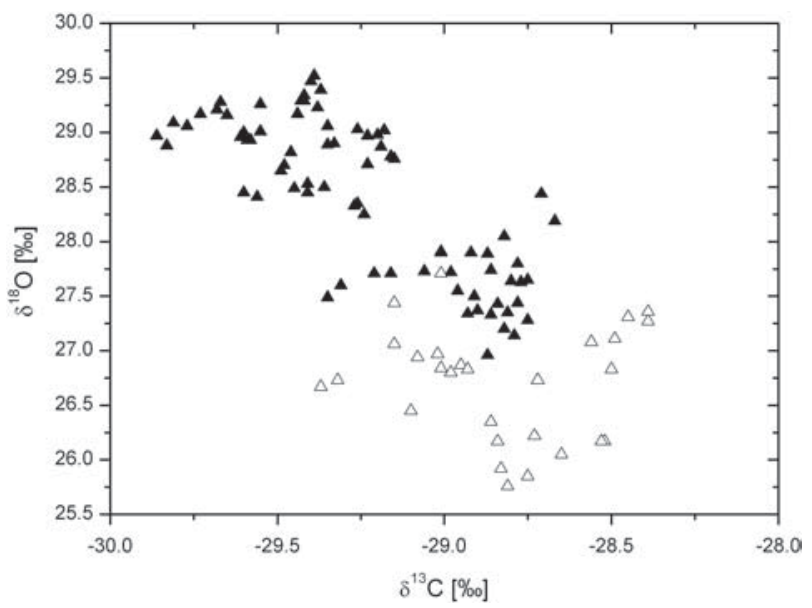

Figure 5. $\delta^{18} \mathrm{O}$ plotted against $\delta^{13} \mathrm{C}$ in the tree-ring wood for the growing season 2007. The correlation coefficient $r$ amounts to -0.76 $(P<0.001)$ for the whole growing season (phases 1 and 2$)$ and for the time period with full sugar export and trunk growth (phase $2=$ DOY 151 to $222=31$ May to 10 August $)$ to $-0.77(P<0.001)$. in contrast, no significant correlation between $\delta^{13} \mathrm{C}$ in LWSOM, LTOM or phloem OM and any of the meteorological parameters determined. $\delta^{18} \mathrm{O}$ in tree-ring whole wood was weakly positively correlated to VP $(r=0.38 ; P<0.01)$, whereas $\delta^{13} \mathrm{C}$ showed a weak negative correlation $(-0.25 ; P<0.05)$.

\section{Discussion}

\section{Towards a mechanistic explanation of seasonal} variations at the leaf level

Our first objective was to link the oxygen isotope signal in leaf water to leaf physiology and environmental conditions. To assess the factors that control evaporative ${ }^{18} \mathrm{O}$ enrichment in the lamina leaf water, we compared observed $\Delta^{18} \mathrm{O}$ with values obtained from a model taking into account the Péclet effect. There is a large body of recent literature applying evaporative enrichment models during the diel courses to explain shortterm patterns of oxygen isotope enrichment (e.g., Cernusak et al. 2005, Farquhar and Cernusak 2005, Barnard et al. 2007, Gessler et al. 2007). However, on a seasonal basis, less information on the applicability of enrichment models is available and, thus far, only conifers have largely been examined (Pendall et al. 2005, Brandes et al. 2007). With our approach, we have shown that inferences drawn from patterns in leaf water enrichment improve relative to simple correlation analysis with $\mathrm{rH}$ when we exploit models that take into account fractionation associated with the phase transition of water molecules, fractionation associated with the diffusion of water isotopologies through the stomata and leaf boundary layer (Craig and Gordon 1965, Dongmann et al. 1974), and the transpiration-driven Péclet effect. As a consequence, our data revealed that the interplay between physiology (e.g., stomatal conductance, transpiration) and environmental conditions (e.g., rH) clearly governed the seasonal oxygen isotope signal imprinted in leaf water during midday. As isostorage (Farquhar and Cernusak 2005) in the leaf is not likely to occur during this time of day, the application of non-steady-state models is not necessary (Gessler et al. 2007).

Newly produced assimilates are assumed to carry the isotopic signature of leaf water present at the time when they were produced, including the equilibrium fractionation factor $\left(\varepsilon_{\mathrm{wc}}\right)$ (Sternberg and Deniro 1983, Yakir and Deniro 1990). A continuous decrease in correlation with leaf water is observed (Table 1) when following the $\delta^{18} \mathrm{O}$ signature from leaf water to the fast turnover organic matter pool (LWSOM) and to structural organic matter (LTOM). In addition, the amplitude of variation in $\delta^{18} \mathrm{O}$ also decreased from leaf water to LWSOM and LTOM (Figure $3 b$ ). These observations are consistent with the findings of Barnard et al. (2007) for $\delta^{18} \mathrm{O}$ in field-grown Scots pine on a diel scale. The dampening of the amplitude in the soluble organic matter isotopic signal can be explained by the significantly longer turnover times of LWSOM compared with 
leaf water (Barnard et al. 2007). The mean ${ }^{18} \mathrm{O}$ enrichment of LWSOM above leaf water during the whole growing season amounts to $\sim 34 \%$ and is thus higher than the expected $27 \%$. Our finding might be attributed to the presence of organic compounds other than carbohydrates in the water soluble fraction obtained, causing differences in the $\delta^{18} \mathrm{O}$ isotope composition (Schmidt et al. 2001).

\section{Uncoupling of the physiological signal from leaves to tree rings}

On the way from LWSOM to trunk phloem, the isotope signal imprinted in the canopy was lost, and the temporal trend in the phloem $\delta^{18} \mathrm{O}$ values was even opposite to trends of values in the leaves (see Figure 3, Table 1). In contrast, phloem $\delta^{18} \mathrm{O}$ correlated well with the $\delta^{18} \mathrm{O}$ in soil and xylem water, which might be considered as an indicator that the source water isotope signal became dominant in the phloem. The calculation of the exchange rate $\left(p_{\mathrm{ex}}^{\text {phloem }}\right)$ between organic matter and xylem water during the transfer of sugars from the leaf to the phloem showed that during most of the growing season clearly $<50 \%$ of organic oxygen originated from non-enriched xylem water. As a consequence, we cannot conclude that the source water signal entirely overwrites the leaf water signal. Nevertheless, the exchange rate seemed to be highly variable and strongly decreased from spring to midsummer, thus leading to the observed uncoupling of the phloem $\delta^{18} \mathrm{O}$ signal from the canopy. $\delta^{18} \mathrm{O}$ of phloem organic matter is, in contrast, reasonably well correlated with $\delta^{18} \mathrm{O}$ in the wood in the tree ring (Table 1). Consequently, we have good reason to assume that processes upstream of cellulose/wood synthesis are mainly responsible for the lack in correlation between $\delta^{18} \mathrm{O}$ of leaf assimilates and the tree-ring tissue. We cannot rule out that the use of treering cellulose instead of whole wood might have improved the correlation between phloem OM and tree ring since lignin is incorporated into cell walls after wood cell formation and cellulose deposition, and thus contains a distinct isotopic signal. In addition, allocation of organic matter between and within tree rings (Kagawa et al. 2006a) might cause the intra-annual isotope signal in the whole wood to be blurred compared with cellulose.

Our results clearly demonstrate that the inversion of the seasonal course of phloem and wood $\delta^{18} \mathrm{O}$ has its origin during transport from the canopy to the trunk as already the phloem sugars, which are the original substrate for wood production, are affected. This finding also attests that potential variation in the cellulose-to-lignin ratio during the growing season (e.g., Wilson and Grinsted 1975) is definitively not the only reason for the uncoupling between tree-ring and canopy $\delta^{18} \mathrm{O}$ patterns. It is unlikely, however, that oxygen atom exchange with phloem water occurred during the transport of sucrose along the sieve tubes. In beech, mainly sucrose is transported (Gessler et al. 2004), which does not contain any free carbonyl group and thus cannot exchange oxygen with water. This theoretical consideration is further supported by our exudation approach, which showed no significant differences between exuded sugars incubated for $5 \mathrm{~h}$ in two waters of contrasting $\delta^{18} \mathrm{O}$ (see Materials and methods). If oxygen exchange could take place within the transport fluid in the sieve tubes, we should have observed a comparable exchange (at least to a certain extent) also during our exudation procedure. The widely accepted theory of phloem transport (recently reviewed by van Bel 2003) might, however, offer an explanation for the exchange of organic oxygen atoms with the stem water. It is known that phloem transport is associated with continuous unloading and retrieval of sugars along the transport path (van Bel 2003). A part of the retrieved sugars might have undergone metabolic conversion in the parenchymatic tissues of the twig or trunk with intermediates that might have formed exchangeable carbonyl groups.

Bark photosynthesis and starch remobilization are two other processes that can supply the phloem with additional carbohydrates to the assimilate pool originating from the leaves, and thus might influence our calculated $p_{\mathrm{ex}}^{\text {phloem }}$ values. ${ }^{18} \mathrm{O}$ depletion of phloem sugars compared with leaf soluble organic matter could be partially due to photosynthesis in the bark of twigs and the upper stem, which has been observed in beech (Wittmann et al. 2001). Organic matter refixed in the bark of twigs, where reaction water is not or only slightly enriched, should lead to $\delta^{18} \mathrm{O}$ signatures of sugars well below the enrichment of sugars fixed in leaves (Cernusak et al. 2005), as observed in our study (Figure 3b). We might assume that bark photosynthesis plays a more important role at the very beginning of the growing season when leaves are not fully developed yet and can therefore explain the stronger relative ${ }^{18} \mathrm{O}$ depletion of phloem OM during that period (Figures 3 and 4). Moreover, the contribution of remobilized storage starch from stem storage pools to phloem sugar transport would explain ${ }^{18} \mathrm{O}$ depletion of phloem compared with leaf sugars. Indeed, during starch remobilization 5 out of 11 oxygen atoms in sucrose generated from starch are exchanged with the surrounding non-enriched water (Gessler et al. 2007). Strong contributions of remobilized organic matter from storage tissues in spring, and a subsequent reduction of the importance of this carbohydrate source towards summer (Helle and Schleser 2004), might also explain the temporal pattern of ${ }^{18} \mathrm{O}$ depletion in phloem OM and thus the calculated $p_{\mathrm{ex}}^{\text {phloem }}$ values. Such decoupling between canopy and trunk phloem $\delta^{18} \mathrm{O}$ as well as the ${ }^{18} \mathrm{O}$ depletion in phloem OM has not been observed in the coniferous species P. sylvestris (Brandes et al. 2007, Gessler et al. 2009a) during the growing season. This might be attributed to a lower contribution of sugars originating from bark photosynthesis and/or starch remobilization to phloem transport in that species. 
Both $\delta^{13} \mathrm{C}$ and $\delta^{18} \mathrm{O}$ reflect seasonal changes in the partitioning of assimilates

Leaf $\delta^{13} \mathrm{C}$ (LWSOM and LTOM) showed clear seasonal phases as previously reported by Helle and Schleser (2004). We defined here phase 1 as the period at the beginning of the growing season, when the $\delta^{13} \mathrm{C}$ isotopic signature of the leaf decreased and the phloem sugar content increased. The decrease in $\delta^{13} \mathrm{C}$ of leaf tissues was likely due to a progressive shift from starchderived carbon (which can be enriched in $\delta^{13} \mathrm{C}$ by up to $4 \%$ o compared with triose-P originating directly from the CalvinBenson cycle (Gleixner et al. 1998)) to carbon from recent assimilation. We then assume that during phase 1 the developing leaves turned from a net carbon sink to a source. During this phase, Helle and Schleser (2004) observed a seasonal peak in $\delta^{13} \mathrm{C}$-indicating the incorporation of starch-derived carbon into the growing tissue - not only in leaves but also in tree-ring cellulose. In fact, we also found the highest $\delta^{13} \mathrm{C}$ seasonal values in the wood of the tree ring in phase 1 . We defined phase 2 as the period when maximum sugar export is reached and wood formation is still in progress. In phase $2, \delta^{13} \mathrm{C}$ decreased in the total organic matter in leaves as well as in the tree-ring tissue (Figure 2). During this phase, recent assimilates, which are depleted in ${ }^{13} \mathrm{C}$ compared with starch, are used to turn over leaf organic matter and are also exported from leaves as freshly formed carbohydrates. Their gradual incorporation into newly formed cell wall material in the tree ring as well as in structural organic matter in the leaf is likely to lead to the continuous decline of $\delta^{13} \mathrm{C}$ in organic matter, as already observed by Helle and Schleser (2004). This common origin of carbohydrates for leaf and treering production also led to a reasonably high correlation in $\delta^{13} \mathrm{C}$ between LTOM and tree-ring whole wood (Table 1).

We can conclude that the strong correlation between $\delta^{13} \mathrm{C}$ and $\delta^{18} \mathrm{O}$ in the tree ring (Figure 5) also supports this explanation. In phase 1 , when starch-derived carbon resulted in ${ }^{13} \mathrm{C}$ enrichment of the wood, $\delta^{18} \mathrm{O}$ values are lowest. The initial low $\delta^{18} \mathrm{O}$ values might be due to the high rates of partial exchange of carbonyl oxygen with trunk water during starch breakdown, as explained previously. The incorporation of newly assimilated organic matter into the tree ring as stem growth proceeds then explains the observed increase in $\delta^{18} \mathrm{O}$ together with the decrease in $\delta^{13} \mathrm{C}$. The lack of such a negative correlation in isotopes present in leaves does not preclude comparable carbohydrate dynamics in this tissue. We observed a seasonal course of $\delta^{13} \mathrm{C}$ that is comparable between wood and leaves, whereas no ${ }^{18} \mathrm{O}$ depletion was observed in LTOM in early spring. However, for our hypothesis of a common origin in carbohydrates for leaf and tree-ring production to be consistent, we have to postulate that when the relatively ${ }^{18} \mathrm{O}$ depleted sucrose originating from trunk starch storage pools is further processed in the developing leaves, oxygen atoms can exchange between the ${ }^{18} \mathrm{O}$ enriched leaf water and the carbonyl groups of glucose, fructose and triose-phosphate (Hill et al. 1995).
As phloem sugars are the $C$ source for wood formation, it should be assumed that $\delta^{13} \mathrm{C}$ in phloem OM is related to wood $\delta^{13} \mathrm{C}$, as we observed for the oxygen isotope signal. Moreover, phloem sugars are the $C$ source for leaf OM (when leaves are developing in spring) or they originate from leaf assimilates (when leaves are fully developed); as a consequence, comparable temporal patterns in leaf and phloem $\delta^{13} \mathrm{C}$ could be expected. While phloem $\delta^{13} \mathrm{C}$ was closely related to $\delta^{13} \mathrm{C}$ of LWSOM during phase 2 , the expected shift from ${ }^{13} \mathrm{C}$ enrichment at the beginning of the growing season (starch-derived carbon) to more negative $\delta^{13} \mathrm{C}$ values before or during phase 2 (new assimilates) was not observed. As a consequence, and in contrast to leaf $\mathrm{OM}, \delta^{13} \mathrm{C}$ of phloem organic matter was only weakly related to $\delta^{13} \mathrm{C}$ of the wood in the tree ring. A possible explanation for the observed temporal pattern of phloem $\delta^{13} \mathrm{C}$ might be that the 'starch $\delta^{13} \mathrm{C}$ signature' in the phloem is only visible at a very early period of the year that had already occurred before our first sampling date. The finding that phloem sugars are generally ${ }^{13} \mathrm{C}$ enriched as compared to leaf organic matter as observed here during most of the growing season agrees with the assumption of Hobbie and Werner (2004) that mainly ${ }^{13} \mathrm{C}$ depleted carbon is allocated to immobile compounds in the leaves, which in turn results in ${ }^{13} \mathrm{C}$ enriched sugars being exported to the phloem.

Helle and Schleser (2004) defined their phase 3 of tree-ring seasonality as the period when $\delta^{13} \mathrm{C}$ in the tree ring increases at the end of the growing season due to incorporation of new starch-derived carbon. We could not clearly observe such a pattern in our intra-annual tree-ring series. It might be assumed that incorporation of storage carbon at the end of tree growth largely depends on the availability of recent assimilates in a given year; as a consequence, an increase in $\delta^{13} \mathrm{C}$ might be observed in some years and not in others. As we could not see a reduction in phloem sugar content or an increase in $\delta^{13} \mathrm{C}$ of phloem OM, we might assume that there was no restriction in the supply of freshly assimilated carbon and thus no need to switch to stored reserves at the end of the trunk growth period. Accordingly, we have redefined phase 3 of the growing season as the period after the end of stem growth, when the sugar concentration in the phloem was still close to the maximum levels. During this period, total and water soluble organic matter in the leaves became further depleted in ${ }^{13} \mathrm{C}$ until senescence in October, as previously observed for beech leaves (Keitel et al. 2003).

The deposition of carbon derived from starch (relatively enriched in ${ }^{13} \mathrm{C}$ ) in spring and the gradually increasing incorporation of newly assimilated $C$ (relatively depleted in ${ }^{13} \mathrm{C}$ ) in leaf tissue and the tree ring during the rest of the growing season most likely prevented $\delta^{13} \mathrm{C}$ in both tissues from being closely related to intra-annual variations in environmental drivers. We thus have to conclude that in a deciduous species, plant internal physiology, namely timing of the use of 
remobilized storage $C$ for trunk growth, has much stronger effects on the intra-annual $\delta^{13} \mathrm{C}$ signal than in coniferous trees (Barbour et al. 2002, Gessler et al. 2009a). These internal carbon dynamics might overwrite seasonal influences of climate, at least in years with no extreme drought periods and rather moderate variations of the meteorological conditions during the growing season (Figure 1). The extent to which stronger variations of the environmental conditions during the growing season modify the intra-annual pattern of $\delta^{13} \mathrm{C}$ (and $\left.\delta^{18} \mathrm{O}\right)$ in tree rings of beech needs to be tested for longer chronologies and preferably at different sites with contrasting climate and soil conditions. Nevertheless, our results do not discourage the use of tree-ring $\delta^{13} \mathrm{C}$ in European beech for inter-annual climate reconstruction (e.g., Saurer et al. 1997), especially when late wood material is used (Helle and Schleser 2004). However, the application of high-resolution intraannual $\delta^{18} \mathrm{O}$ and $\delta^{13} \mathrm{C}$ tree-ring data in combination with isotope models as described by Ogee et al. (2009) with Pinus pinaster for reconstructing tree- and stand-level carbon balance should be taken with caution in deciduous trees. This approach definitely needs a deeper quantitative understanding of tree internal storage pools and assimilate partitioning.

\section{Concluding remarks}

In conclusion, we could not find a continuously constant relation of $\delta^{18} \mathrm{O}$ between canopy and trunk organic matter pools in European beech within the growing season. Not only the tree ring but also the phloem OM was uncoupled in their seasonal $\delta^{18} \mathrm{O}$ signal from the leaves. We postulate this to be caused mainly by the seasonally varying contribution of different carbohydrate sources to tree-ring formation. These carbohydrates strongly exchange oxygen atoms with xylem water either during formation (stem photosynthates) or during processing (remobilized starch). A high contribution of remobilized starch to tree-ring and leaf formation in early spring and a gradual switch to recent assimilates are also supported by the $\delta^{13} \mathrm{C}$ data. Further research on the actual processes involved in oxygen atom exchange and isotope fractionation between leaves and the phloem would help to determine the conditions under which they can exert a strong influence on the wood isotopic signal, as observed in the present study.

\section{Supplementary data}

Supplementary data for this article are available at Tree Physiology online.

\section{Acknowledgments}

We would like to thank Wolfgang Kornberger for his help with mass spectrometer measurements, Johannes Schumacher for his help with sample preparation and Prof. Fink for the use of the microtome. The experiments were financially supported by the Deutsche Forschungsgemeinschaft (contract numbers GE 1090/5-1, 8-1 and 9-1). J.P.F. was supported by a Marie Curie IEF (6th FP, EU) and a Ramón y Cajal contract (MCINN, Spain).

\section{References}

Barbour, M. 2007. Stable oxygen isotope composition of plant tissue: a review. Funct. Plant Biol. 34:83-94.

Barbour, M., R. Fischer, K. Sayre and G. Farquhar. 2000. Oxygen isotope ratio of leaf and grain material correlates with stomatal conductance and grain yield in irrigated wheat. Aust. J. Plant Physiol. 27:625-637.

Barbour, M., A. Walcroft and G. Farquhar. 2002. Seasonal variation in $\delta^{13} \mathrm{C}$ and $\delta^{13} \mathrm{O}$ of cellulose from growth rings of Pinus radiata. Plant, Cell Environ. 25:1483-1499.

Barnard, R., Y. Salmon, N. Kodama, K. Sörgel, J. Holst, H. Rennenberg, A. Gessler and N. Buchmann. 2007. Evaporative enrichment and time lags between $\delta^{13} \mathrm{O}$ of leaf water and organic pools in a pine stand. Plant, Cell Environ. 30:539-550.

Bowling, D., D. Pataki and J. Randerson. 2008. Carbon isotopes in terrestrial ecosystem pools and $\mathrm{CO}_{2}$ fluxes. New Phytol. 178:28-40.

Brandes, E., N. Kodama, K. Whittaker, C. Weston, H. Rennenberg, C. Keitel, M. Adams and A. Gessler. 2006. Short-term variations in the isotope signatures of organic matter allocated from the leaves to the axis of Pinus sylvestris - effects of photosynthetic and post-photosynthetic carbon isotope fractionation. Global Change Biol. 12: 1922-1939.

Brandes, E., J. Wenninger, P. Koeniger, D. Schindler, H. Rennenberg, C. Leibundgut, H. Mayer and A. Gessler. 2007. Assessing environmental and physiological controls over water relations in a Scots pine (Pinus sylvestris L.) stand through analyses of stable isotope composition of water and organic matter. Plant, Cell Environ. 30:113-127.

Brugnoli, E., K. Hubick, S. von Caemmerer, S. Wong and G. Farquhar. 1988. Correlation between the carbon isotope discrimination in leaf starch and sugars of C-3 plants and the ratio of intercellular and atmospheric partial pressures of carbon-dioxide. Plant Physiol. 88:1418-1424.

Burk, R. and M. Stuiver. 1981. Oxygen isotope ratios in trees reflect mean annual temperature and humidity. Science 211:1417-1419.

Cernusak, L., D. Arthur, J. Pate and G. Farquhar. 2003. Water relations link carbon and oxygen isotope discrimination to phloem sap sugar concentration in Eucalyptus globulus. Plant Physiol. 131: 1544-1554.

Cernusak, L., G. Farquhar and J. Pate. 2005. Environmental and physiological controls over oxygen and carbon isotope composition of Tasmanian blue gum, Eucalyptus globulus. Tree 25:129-146.

Cernusak, L., G. Tcherkez, C. Keitel, et al. 2009. Viewpoint: Why are non-photosynthetic tissues generally $\mathrm{C}-13$ enriched compared with leaves in C-3 plants? Review and synthesis of current hypotheses. Funct. Plant Biol. 36:199-213.

Craig, H. and L. Gordon. 1965. Deuterium and oxygen-18 variations in the ocean and the marine atmosphere. In Proceedings of the Conference on Stable Isotopes in Oceanographic Studies and Palaeotemperatures in Spoletto, 1965. Ed. E. Tongiorgi. Consiglio Nazionale delle Ricerche Laboratorio di Geologia Nucleare, Pisa, Italy, pp. 9-130.

Dawson, T., J. Ward and J. Ehleringer. 2004. Temporal scaling of physiological responses from gas exchange to tree rings: a gender-specific study of Acer negundo (Boxelder) growing under different conditions. Funct. Ecol. 18:212-222.

Devaux, M., J. Ghashghaie, D. Bert, C. Lambrot, A. Gessler, C. Bathellier, J. Ogée and D. Lousteau. 2009. Carbon stable isotope ratio of phloem sugars in mature pine trees throughout the growing season: 
comparison of two extraction methods. Rapid Commun. Mass Spectrom. 23:2511-2518.

Dongmann, G., H. Nurnberg, H. Förstel and K. Wagner. 1974. On the enrichment of $\mathrm{H}_{2}{ }^{18} \mathrm{O}$ in the leaves of transpiring plants. Rad. Environ. Biophys. 11:41-52.

Ehleringer, J., J. Roden and T. Dawson. 2000. Assessing ecosystemlevel water relations through stable isotope ratio analyses. Springer Verlag, New York, pp 181-198.

Farquhar, G. and L. Cernusak. 2005. On the isotopic composition of leaf water in the non-steady state. Funct. Plant Biol. 32:293-303.

Farquhar, G. and J. Lloyd. 1993. Carbon and oxygen isotope effects in the exchange of carbon dioxide between terrestrial plants and the atmosphere. In Stable Isotopes and Plant Carbon Water Relations. Eds. J.R. Ehleringer, A.E. Hall and G.D. Farquhar. Academic Press, San Diego, CA, USA, pp 47-70.

Farquhar, G., M. O'Leary and J. Berry. 1982. On the relationship between carbon isotope discrimination and the intercellular carbon-dioxide concentration in leaves. Aust. J. Plant Physiol. 9:121-137.

Farquhar, G., M. Barbour and B. Henry. 1998. Interpretation of oxygen isotope composition of leaf material. In Stable Isotopes-Integration of Biological, Ecological and Geochemical Processes. Ed. H. Griffiths. Bios Scientific Publishers, Oxford, pp 24-27.

Ferrio, J., and J. Voltas. 2005. Carbon and oxygen isotope ratios in wood constituents of Pinus halepensis as indicators of precipitation, temperature and vapour pressure deficit. Tellus Series B-Chem. Phys. Meteorol. 57:164-173.

Ferrio, J., M. Cuntz, C. Offermann, R. Siegwolf, M. Saurer and A. Gessler. 2009. Effect of water availability on leaf water isotopic enrichment in beech seedlings shows limitations of current fractionation models. Plant, Cell Environ. 32:1285-1296.

Gessler, A., S. Schrempp, A. Matzarakis, H. Mayer, H. Rennenberg and M. Adams. 2001. Radiation modifies the effect of water availability on the carbon isotope composition of beech (Fagus sylvatica). New Phytol. 150:653-664.

Gessler, A., H. Rennenberg and C. Keitel. 2004. Stable isotope composition of organic compounds transported in the phloem of European beech-evaluation of different methods of phloem sap collection and assessment of gradients in carbon isotope composition during leaf-to-stem transport. Plant Biol. 6:721-729.

Gessler, A., A.D. Peuke, C. Keitel and G.D. Farquhar. 2007. Oxygen isotope enrichment of organic matter in Ricinus communis during the diel course and as affected by assimilate transport. New Phytol. 174:600-613.

Gessler, A., E. Brandes, N. Buchmann, G. Helle, H. Rennenberg and R. Barnard. 2009a. Tracing carbon and oxygen isotope signals from newly assimilated sugars in the leaves to the tree-ring archive. Plant, Cell Environ. 32:780-795.

Gessler, A., M. Löw, C. Heerdt, et al. 2009b. Within-canopy and ozone fumigation effects on $\delta^{13} \mathrm{C}$ and $\Delta^{18} \mathrm{O}$ in adult beech (Fagus sylvatica) trees: relation to meteorological and gas exchange parameters. Tree Physiol. 29:1349-1365.

Gleixner, G., C. Scrimgeour, H.-L. Schmidt and R. Viola. 1998. Stable isotope distribution in the major metabolites of source and sink organs of Solanum tuberosum L.: a powerful tool in the study of metabolic partitioning in intact plants. Planta 207:241-245.

Grissino-Mayer, H. 2001. Evaluating crossdating accuracy: a manual and tutorial for the computer program COFECHA. Tree-Ring Res. 57:205-221.

Helle, G. and G. Schleser. 2004. Beyond $\mathrm{CO}_{2}$ fixation by Rubisco - an interpretation of ${ }^{13} \mathrm{C} /{ }^{12} \mathrm{C}$ variations in tree rings from novel intraseasonal studies on broad-leaf trees. Plant, Cell Environ. 27:367-380.

Hill, S.A., J.S. Waterhouse, E.M. Field, V.R. Switsur and T. Ap Rees. 1995. Rapid recycling of triose phosphates in oak stem tissue. Plant, Cell Environ. 18:931-936.
Hobbie, E.A. and R.A. Werner. 2004. Intramolecular, compoundspecific, and bulk carbon isotope patterns in C-3 and C-4 plants: a review and synthesis. New Phytol. 161:371-385.

Holm, S. 1979. A simple sequentially rejective multiple test procedure. Scand. J. Stat. 6:65-70.

Holmes, R. 1983. Computer-assisted quality control in tree-ring dating and measurement. Tree-Ring Bull. 43:69-78.

Holst, T., S. Hauser, A. Kirchgäßner, A. Matzarakis, H. Mayer and D. Schindler. 2004. Measuring and modelling plant area index in beech stands. Int. J. Biometeorol. 48:192-201.

Holst, J., R. Grote, C. Offermann, J. Ferrio, A. Gessler, H. Mayer and H. Rennenberg. 2010. Water fluxes within beech stands in complex terrain. Int. J. Biometeorol. 54:23-36.

Jones, H. 1992. Plants and microclimate. Cambridge University Press, Cambridge, UK.

Kagawa, A., A. Sugimoto and T.C. Maximov. 2006a. ${ }^{13} \mathrm{CO}_{2}$ pulselabelling of photoassimilates reveals carbon allocation within and between tree rings. Plant, Cell Environ. 29:1571-1584.

Kagawa, A., A. Sugimoto and T. Maximov. 2006b. Seasonal course of translocation, storage and remobilization of ${ }^{13} \mathrm{C}$ pulse-labeled photoassimilate in naturally growing Larix gmelinii saplings. New Phytol. 171:793-804.

Keitel, C., M.A. Adams, T. Holst, A. Matzarakis, H. Mayer, H. Rennenberg and A. Gessler. 2003. Carbon and oxygen isotope composition of organic compounds in the phloem sap provides a short-term measure for stomatal conductance of European beech Fagus sylvatica L. Plant, Cell Environ. 26:1157-1168.

Keitel, C., A. Matzarakis, H. Rennenberg and A. Gessler. 2006. Carbon isotopic composition and oxygen isotopic enrichment in phloem and total leaf organic matter of European beech (Fagus sylvatica L.) along a climate gradient. Plant, Cell Environ. 29:1492-1507.

Klein, T., D. Hemming, T. Lin, J.M. Grünzweig, K. Maseyk, E. Rotenberg and D. Yakir. 2005. Association between tree-ring and needle $\delta^{13} \mathrm{C}$ and leaf gas exchange in Pinus halapensis under semi-arid conditions. Oecologia 144:45-54.

Korol, R., M. Kirschbaum, G. Farquhar and M. Jeffreys. 1999. Effects of water status and soil fertility on the C-isotope signature in Pinus radiata. Tree Physiol. 19:551-562.

Leavitt, S. 2007. Regional expression of the 1988 US Midwest drought in seasonal $\delta^{13} \mathrm{C}$ of tree rings. J. Geophys. Res. Atmos. 112:D06107.

Leavitt, S.W. and A. Long. 1986. Stable carbon isotope variability in tree foliage and wool. Ecology 67:1002-1010.

Leavitt, S.W. and A. Long. 1991. Seasonal stable-carbon isotope variability in tree rings: possible paleoenvironmental signals. Chem. Geol. (Isot. Geosci. Sect.) 87:59-70.

Li, C., S. Frolking and T.A. Frolking. 1992. A model of nitrous oxide evolution from soil driven by rainfall events: 1 . Model structure and sensitivity. J. Geophys. Res. 97:9759-9776.

Libby, L., L. Pandolfi, P. Payton, J. Marshall, B. Becker and V. GiertzSiebenlist. 1976. Isotopic tree thermometers. Nature 261:284-288.

Loader, N.J. and V.R. Switsur. 1996. Reconstructing past environmental change using stable isotopes in tree-rings. Bot. J. Scotland 48:65-78.

Loader, N.J., V.R. Switsur and E.M. Field. 1995. High-resolution stable isotope analysis of tree rings: implications of 'microdendroclimatology' for palaeoenvironmental research. Holocene 5:457-460.

McCarroll, D. and N. Loader. 2004. Stable isotopes in tree rings. Quaternary Sci. Rev. 23:771-801.

McCarroll, D. and F. Pawellek. 2001. Stable carbon isotope ratios of Pinus sylvestris from northern Finland and the potential for extracting a climate signal from long Fennoscandian chronologies. Holocene 11:517-526.

Nahm, M., T. Holst, A. Matzarakis, H. Mayer, H. Rennenberg and A. Gessler. 2006. Soluble N compound profiles and concentrations 
in European beech (Fagus sylvatica L.) are influenced by local climate and thinning. Eur. J. For. Res. 125:1-14.

Ogee, J., M. Barbour, L. Wingate, et al. 2009. A single-substrate model to interpret intra-annual stable isotope signals in tree-ring cellulose. Plant, Cell Environ. 32:1071-1090.

Pendall, E., G. William and S. Leavitt. 2005. Comparison of measured and modelled variations in pinon pine leaf water isotopic enrichment across a summer moisture gradient. Oecologia 145:605-618.

Poussart, P.F., M.N. Evans and D.P. Schrag. 2004. Resolving seasonality in tropical trees: multi-decade, high resolution oxygen and carbon isotope records from Indonesia and Thailand. Earth Planet. Sci. Lett. 218:301-316.

R Development Team. 2008. R: A language and environment for statistical computing. R Foundation for Statistical Computing, Vienna.

Roden, J.S. 2008. Cross-dating of tree ring $\delta^{18} \mathrm{O}$ and $\delta^{13} \mathrm{C}$ time series. Chem. Geol. 252:72-79.

Roden, J. and J.R. Ehleringer. 1999. Hydrogen and oxygen isotope ratios of tree-ring cellulose for riparian trees grown long-term under hydroponically controlled environments. Oecologia 121:467-477.

Roden, J.S., J. Johnstone and T.E. Dawson. 2009. Intra-annual variation in the stable oxygen and carbon isotope ratios of cellulose in tree rings of coast redwood (Sequoia sempervirens). Holocene 19:189-197.

Rozanski, K., L. Araguás-Araguás and R. Gonfiantini. 1992. Relation between long-term trends of oxygen-18 isotope composition of precipitation and climate. Science 258:981-985.

Saurer, M., S. Borella and M. Leuenberger. 1997. $\delta^{18} \mathrm{O}$ of tree rings of beech (Fagus silvatica) as a record of $\delta^{18} \mathrm{O}$ of the growing season precipitation. Tellus 49:80-92.

Scheidegger, Y., M. Saurer, M. Bahn and R. Siegwolf. 2000. Linking stable oxygen and carbon isotopes with stomatal conductance and photosynthetic capacity: a conceptual model. Oecologia 125: 350-357.

Schmidt, H.-L. 2003. Fundamentals and systematics of the nonstatistical distributions of isotopes in natural compounds. Naturwissenschaften 90:537-552.
Schmidt, H.-L., R. Werner and A. Rossmann. 2001. ${ }^{18} \mathrm{O}$ pattern and biosynthesis of natural plant products. Phytochemistry 58:9-32.

Schneider, S., A. Gessler, P. Weber, D. v. Sengbusch, U. Hanemann and H. Rennenberg. 1996. Soluble N compounds in trees exposed to high loads of N: a comparison of spruce (Picea abies) and beech (Fagus sylvatica) grown under field conditions. New Phytol. 134:103-114.

Sternberg, L. 2009. Oxygen stable isotope ratios of tree-ring cellulose: the next phase of understanding. New Phytol. 181:553-562.

Sternberg, L. and M.J. DeNiro. 1983. Bio-geochemical implications of the isotopic equilibrium fractionation factor between oxygen atoms of acetone and water. Geochim. Cosmochim. Acta 47:2271-2274.

Sternberg, L.D.S., M.J. Deniro and A. Savidge. 1986. Oxygen isotope exchange between metabolites and water during biochemical reactions leading to cellulose synthesis. Plant Physiol. 82:423-427.

Tcherkez, G. and G. Farquhar. 2005. Carbon isotope effect predictions for enzymes involved in the primary carbon metabolism of plant leaves. Funct. Plant Biol. 32:277-291.

Treydte, K., D. Frank, J. Esper, et al. 2007. Signal strength and climate calibration of a European tree-ring isotope network. Geophys. Res. Lett. 34:6.

van Bel, A. 2003. The phloem, a miracle of ingenuity. Plant, Cell Environ. 26:125-149.

White, J.W., J.R. Lawrence and W.S. Broecker. 1994. Modeling and interpreting $\mathrm{D} / \mathrm{H}$ ratios in tree rings: A test case of white pine in northeastern United States. Geochim. Cosmochim. Acta 58: 851-862.

Wilson, A.T. and M.J. Grinsted. 1975. Palaeotemperatures from tree rings and the $\mathrm{D} / \mathrm{H}$ ratio of cellulose as a biochemical thermometer. Nature 257:387-388.

Wittmann, C., G. Aschan and H. Pfanz. 2001. Leaf and twig photosynthesis of young beech (Fagus sylvatica) and aspen (Populus tremula) trees grown under different light regimes. Basic Appl. Ecol. 2: 145-154.

Yakir, D. and M. Deniro. 1990. Oxygen and hydrogen isotope fractionation during cellulose metabolism in Lemna gibba. Plant Physiol. 93:325-332. 